\title{
Projeto de Dados em Bancos de Dados Distribuídos
}

Eduardo José Soler Mesquita

Dissertação submetida em cumprimento parcial dos requisitos para obtenção do grau de Mestre em Matemática Aplicada.

Área de Concentração: Ciência da Computação Orientador: Prof. Dr. Marcelo Finger

- São Paulo, maio de 1998 - 


\section{Projeto de Dados em Bancos de Dados Distribuídos}

Este exemplar corresponde à' versão final da dissertação apresentada por

Eduardo José Soler Mesquita e aprovada pela comissão julgadora.

São Paulo, maio de 1998.

Banca Examinadora:

Prof. Dr. Marcelo Finger (orientador)

IME-USP

Prof. Dr. Alberto H. F. Laender

DCC-UFMG

Prof. Dr. Francisco da Rocha Reverbel

IME -USP 


\section{Projeto de Dados em Bancos de Dados Distribuídos}

por Eduardo José Soler Mesquita

\section{Resumo}

Esta tese propõe o projeto de distribuição de dados no nível conceitual, a partir da utilização de um modelo semântico, o modelo Entidade-Relacionamento.

Nos modelos de dados existentes na literatura, o projeto de distribuição de dados é realizado no nível lógico, o que torna o esquema conceitual obsoleto a partir da geração do esquema lógico. O esquema de fragmentação é construído sobre o esquema lógico, e o modelo conceitual torna-se uma documentação desatualizada do projeto do banco de dados.

Nosso trabalho clarifica a natureza estrutural das fragmentações realizadas no projeto de distribuição de dados e incorpora o modelo conceitual à documentação ativa do projeto. 


\title{
Data Distribution Design in
}

\section{Distributed Databases}

\author{
by Eduardo José Soler Mesquita
}

\begin{abstract}
This work studies the problem of designing the data distribution for distributed databases from the coceptual level, using the well-known semantic model EntityRelationship.

In the literature, data distribution desing is made at the logic level, wich makes the associated model at the conceptual level obsolete once the distribution schema is generated. Fragmentation is the usual process of distributing data, and it is applied only at the logic level. Therefore the database schema at the conceptual level is left out of date.

By bringing the fragmentation process to the comceptual level our work intends to make the conceptual level as living entity throughout the design process abd also during the database life-time. Also, our method clarifies the structural nature of the fragmentation process, a fact that remained hidden in the logic level.
\end{abstract}


Dedico este trabalho a Deus, pela graça da vida e "perfeição" a mim concedidas, e aos meus pais pelo carinho e esforço dispensados à realização dos meus estudos. 


\section{AGRADECIMENTOS}

Ao Prof. Dr. Marcelo Finger, pelo acompanhamento e orientação neste trabalho, e pela amizade com que sempre me considerou.

À minha familia, por todo o apoio e incentivo. Em especial à minha mãe, pela incessante "marcação cerrada" desde o início, e pela correção ortográfica deste trabalho.

Ao meu irmão, Beto, por ter me aturado nestes dois longos anos, e por preparar o jantar às segundas e quartas.

À minha namorada, Maida, pela paciência e carinho, e pela ajuda na elaboração de algumas figuras (que não são poucas).

À minha amiga Loreley, pela atenção e companheirismo, e por sujeitar-se à massacrante tarefa de revisar esta dissertação.

À FAPESP, pelo apoio financeiro concedido.

A todos os funcionários do IME, que com o seu trabalho contribuíram, direta ou indiretamente, para a realização do meu.

A todos os professores, amigos e colegas de aula, em especial aos amigos do vôlei, pela companhia carinhosa durante este período. 


\section{ÍNDICE}

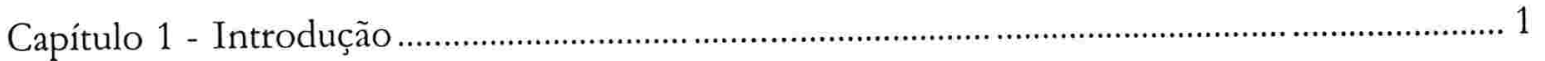

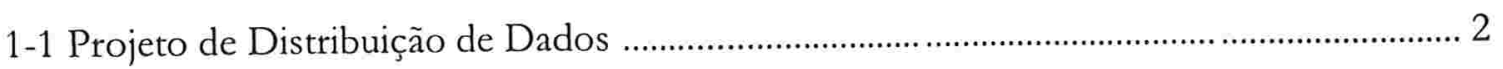

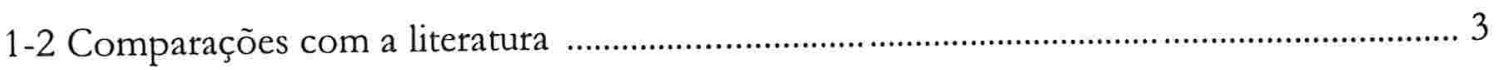

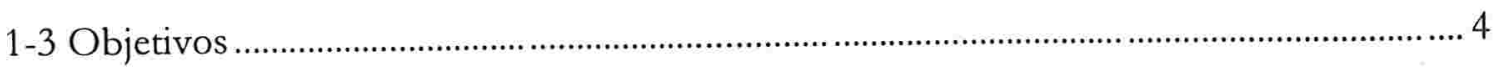

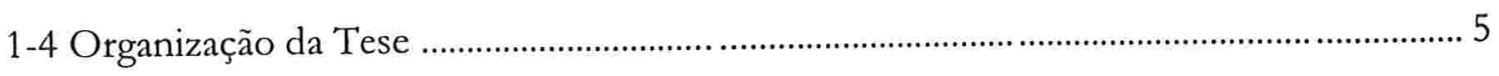

Capítulo 2 - O Modelo Entidade-Relacionamento …................................................................... 7

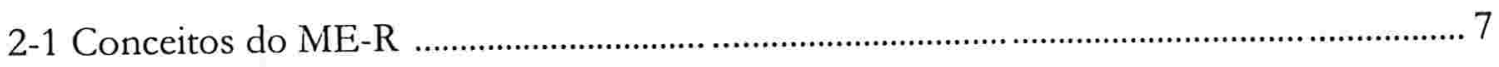

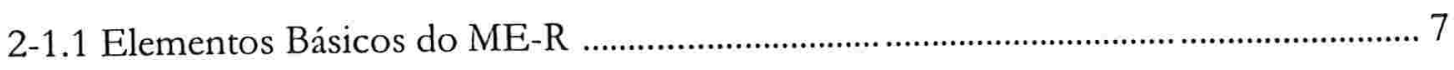

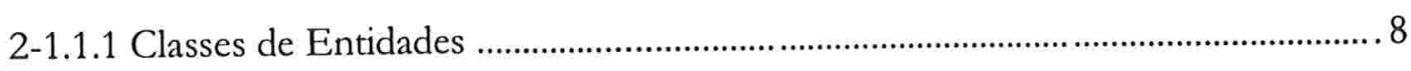

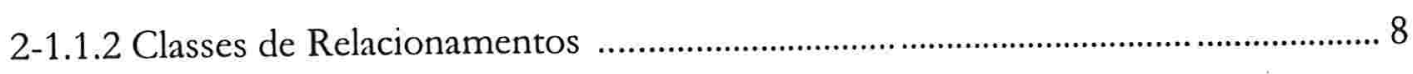

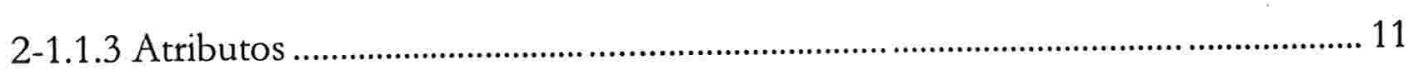

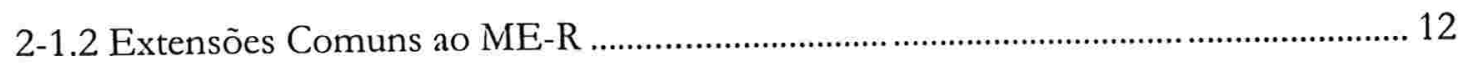

2-1.2.1 Hierarquia de Generalização ........................................................................... 12

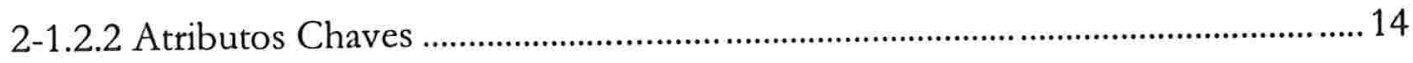

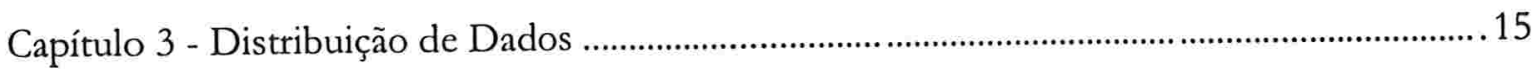

3-1 Arquitetura de Referência para Bancos de Dados Distribuídos ........................................ 15

3-1.1 O Modelo Relacional de Dados …............................................................................ 17

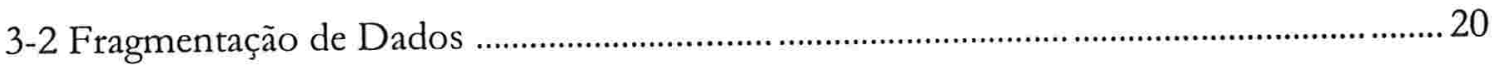

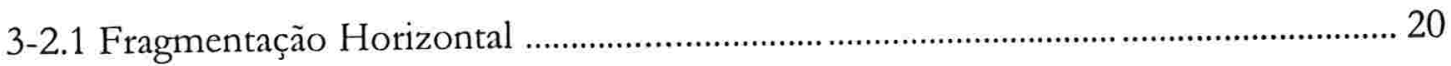

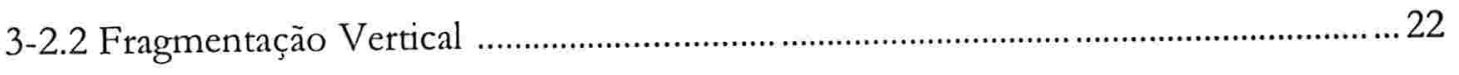

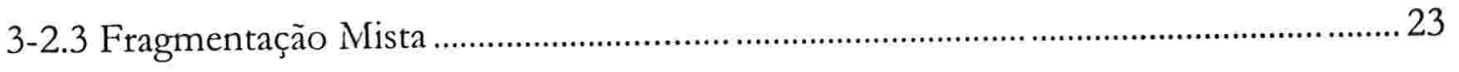

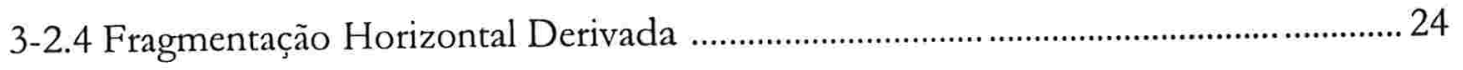

Capítulo 4 - Pré-Requisitos à Fragmentação no ME-R ............................................................... 26 
4-1 Modelo Relacional versus Modelo ER

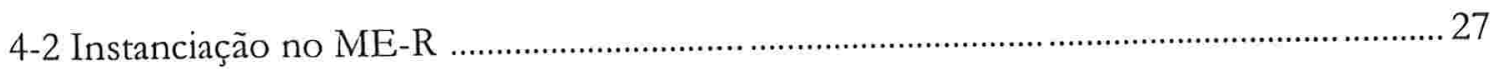

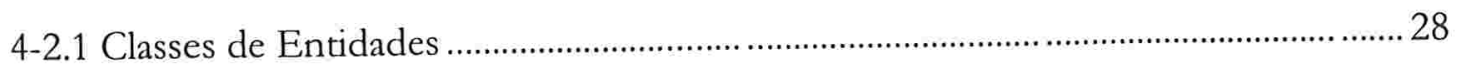

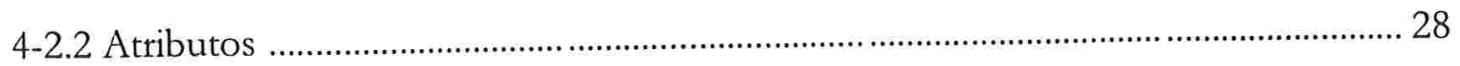

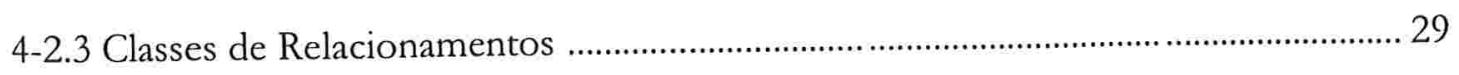

4-2.4 Hierarquias de Generalização .................................................................................... 29

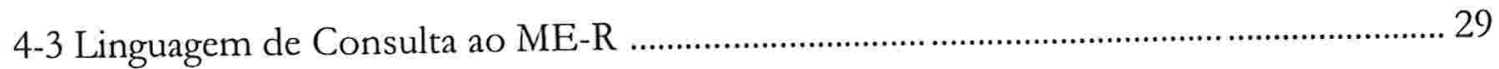

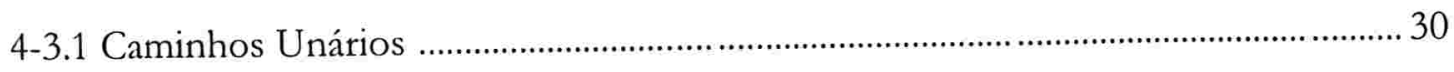

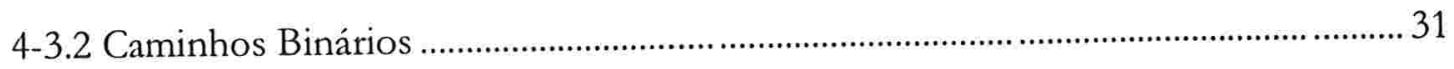

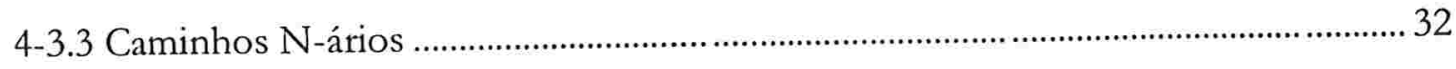

Capítulo 5 - Fragmentação Primária do Diagrama ER …………………...................................... 34

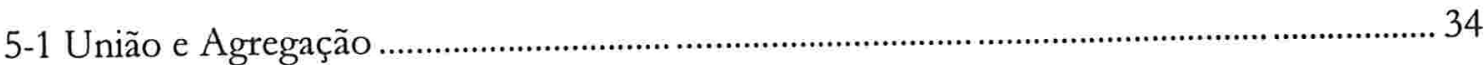

5-2 Fragmentação de Classes de Entidades ............................................................................... 36

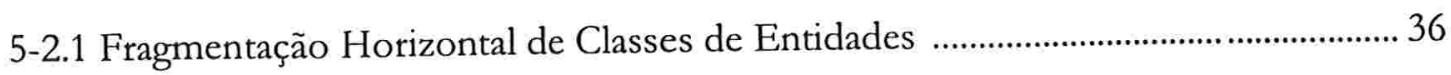

5-2.2 Fragmentação Vertical de Classes de Entidades ....................................................... 38

5-3 Fragmentação de Hierarquias de Generalização ................................................................. 40

5-3.1 Fragmentação Horizontal de Hierarquias de Generalização ……………………….... 40

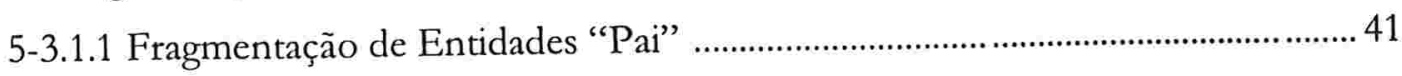

5-3.1.2 Fragmentação de Entidades "Filhas" ................................................................... 42

5-3.2 Fragmentação Vertical de Hierarquias de Generalização …………………………... 44

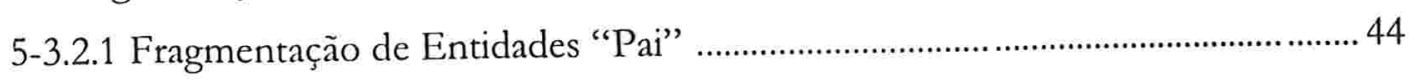

5-3.2.2 Fragmentação de Entidades "Filhas" ................................................................... 46

Capítulo 6 - Fragmentação Derivada Estrutural do Diagrama ER .............................................. 47

6-1 Fragmentação Derivada Primária ……………………...................................................... 47

6-2 Fragmentação de Elementos Auto-Relacionados ……………………………………....... 50 


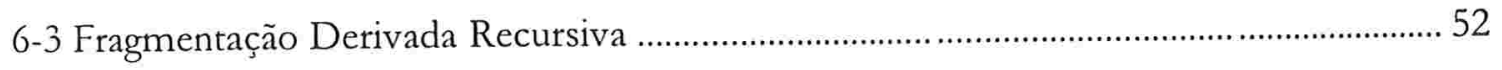

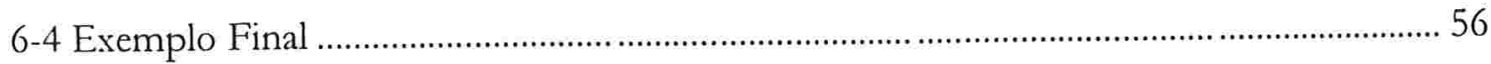

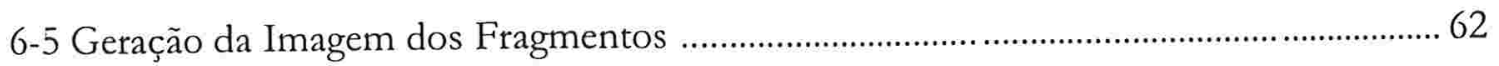

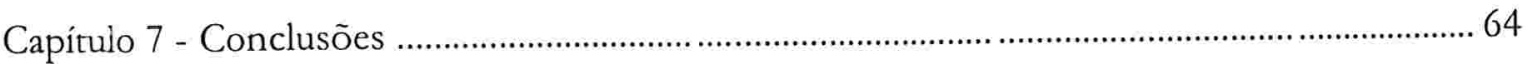

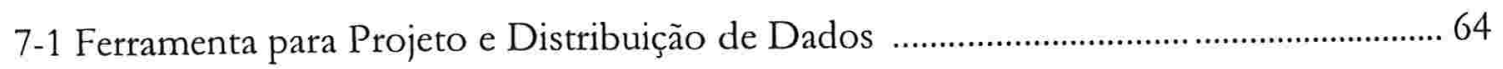

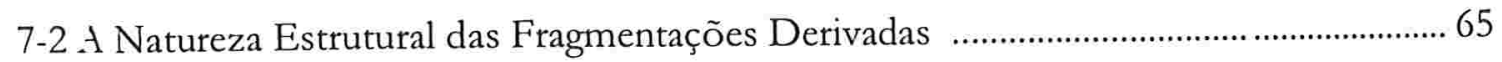

7-3 Incorporação do Esquema Conceitual na Vida do Banco de Dados …………………....6 66

7-4 Criação de uma Base Teórica para a Manipulação de Dados ..........................................67

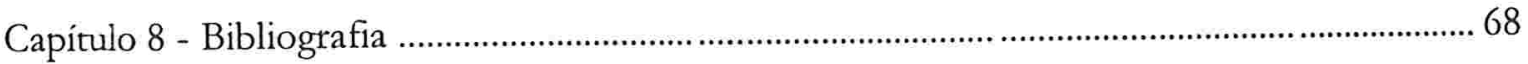




\section{ÍNDICE DE FIGURAS}

Figura 1: Fases de Projeto de um Banco de Dados 1

Figura 2: Fases de Projeto de um BD Conceitual ........................................................................ 5

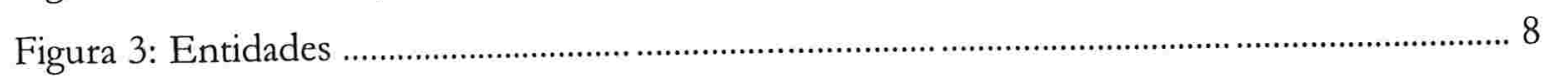

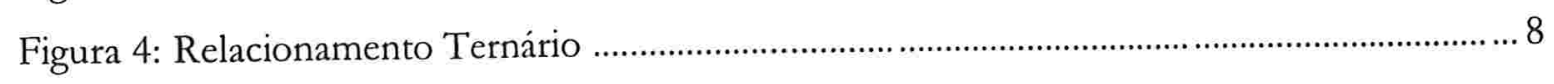

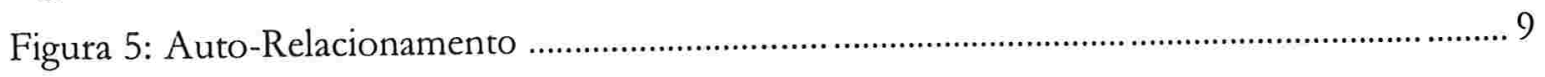

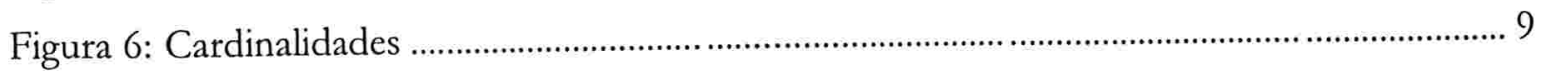

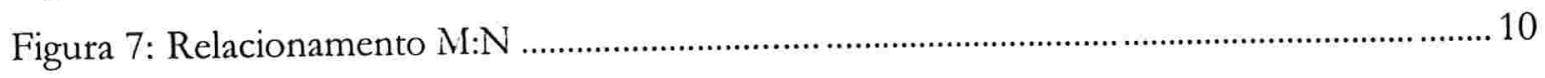

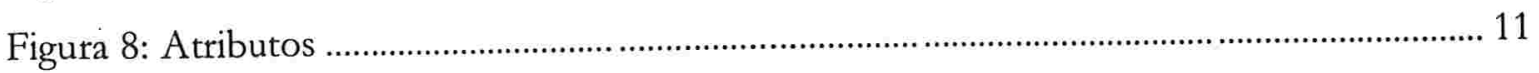

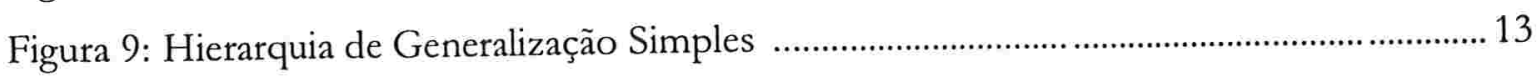

Figura 10: Hierarquia de Generalização Composta ................................................................... 13

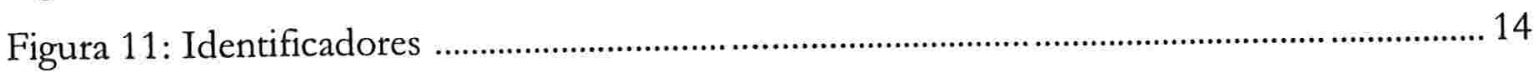

Figura 12: Arquitetura de Referência para Bancos de Dados Distribuídos ................................ 16

Figura 13: Fragmentos e Imagem Física para uma Relação Global .......................................... 17

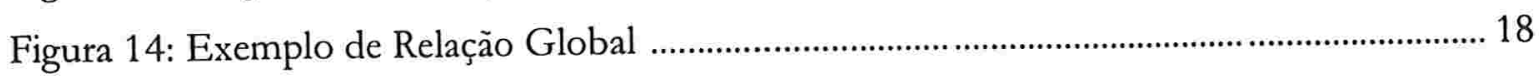

Figura 15: Árvore de Fragmentação ……………................................................................... 24

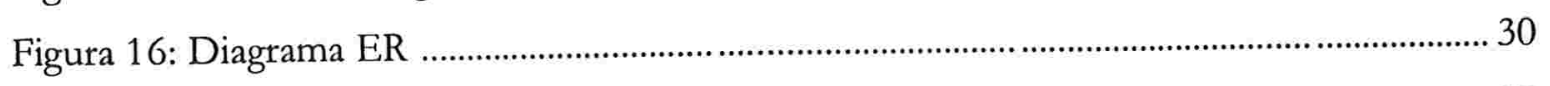

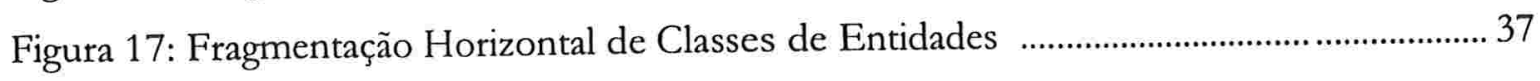

Figura 18: Associação Implícita entre Diagramas (Frag. Horizontal Entidades) ..................... 38

Figura 19: Fragmentação Vertical de Classes de Entidades ........................................................... 39

Figura 20: Operação de Agregação dos Fragmentos ………………………………………….... 40

Figura 21: Fragmentação Horizontal de uma Entidade "Pai" em uma Hierarquia ................... 41

Figura 22: Associação Implícita entre Diagramas (Frag. Horizontal Hierarquias) ................... 42

Figura 23: Fragmentação Horizontal de uma Entidade "Filha" em uma Hierarquia ............... 43

Figura 24: Associação Implícita entre Diagramas (Frag. Horizontal Hierarquias) .................... 43

Figura 25: Fragmentação Vertical de uma Entidade "Pai" em uma Hierarquia ........................ 45

Figura 26: Associação Implícita entre Diagramas (Frag. Vertical Hieraquias) .......................... 45

Figura 27: Fragmentação Horizontal Derivada Primária ............................................................ 48

Figura 28: Fragmentação Vertical Derivada Primária ……………………….............................. 49

Figura 29: Fragmentação de um Auto-Relacionamento ............................................................ 50 
Figura 30: Relacionamento Binário 50

Figura 31: Fragmentação Horizontal (1) em Auto-Relacionamento 51

Figura 32: Fragmentação Horizontal (2) em Auto-Relacionamento 51

Figura 33: Diagrama ER Final (Auto-Relacionamento) …….................................................... 52

Figura 34: Propagação (1) da Fragmentação pelo Diagrama ER ………………….................... 54

Figura 35: Propagação (2) da Fragmentação pelo Diagrama ER ................................................ 55

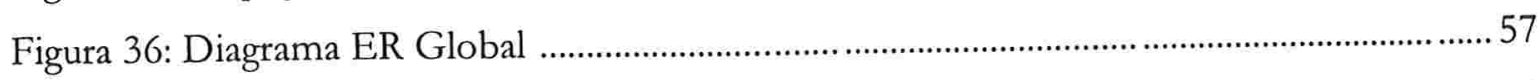

Figura 37: Fragmentação Horizontal Inicial …………............................................................. 58

Figura 38: Fragmentação Horizontal Derivada ........................................................................... 60

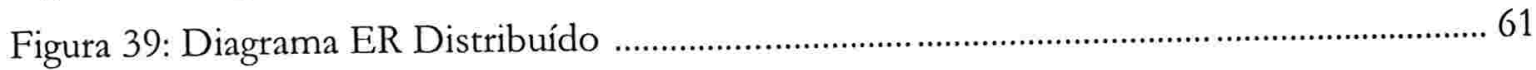

Figura 40: Diagrama ER para Geração da Imagem dos Fragmentos .........................................62

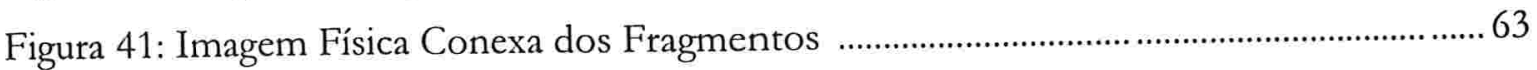

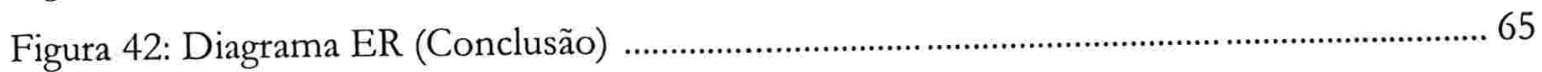


Capítulo 1

\section{Introdução}

A modelagem de bancos de dados no nível conceitual já existe na literatura desde a proposta de modelo de Peter Chen [1], e vem sendo enriquecida e expandida ao longo dos anos.

O projeto de um banco de dados pode ser dividido em três fases. A primeira fase, chamada de projeto conceitual, produz uma representação em alto nível de abstração da realidade. A segunda fase, denominada projeto lógico, traduz esta representação em especificações que podem ser implementadas e processadas por um sistema de computação. A terceira fase, chamada de projeto físico, determina as estruturas de armazenamento físico e métodos de acesso eficientes ao conteúdo do banco de dados através de dispositivos de armazenamento secundários. As fases de projeto são ilustradas na Figura 1.

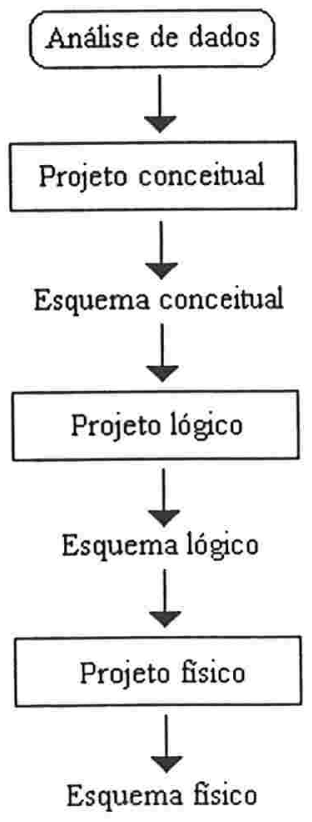

Figura 1: Fases de Projeto de um Banco de Dados

Até bem pouco tempo atrás, os chamados "modelos semânticos" de dados, em particular o modelo entidade-relacionamento (ME-R), eram tratados meramente como 


\section{Capítulo 1 - Introdução}

ferramentas de projeto e, tão logo o esquema do banco de dados fosse gerado, era abandonado, tornando-se apenas uma parte da documentação do projeto. Mais recentemente, vem-se tentando expandir o uso de modelos no nível conceitual também para a manipulação dos dados, bem como o projeto de aplicativos para bancos de dados. As vantagens obtidas com esta expansão são, dentre outras:

- o modelo conceitual torna-se uma documentação "viva" do projeto, ou seja, ele acompanha a vida do banco de dados, evoluindo com o mesmo. Anteriormente, era normal existir uma discrepância, ou mesmo contradições, entre o modelo conceitual, que dava origem apenas à versão original do banco de dados, e a versão ativa que continha depurações e refinamentos posteriores à versão original;

- obtém-se uma independência de plataforma, visto que o projeto sendo realizado no nível conceitual é mais abstrato e independe, em tese, do banco de dados subjacente. Isto traz vantagens de aprendizado na metodologia de projeto e portanto, um programador que aprenda a metodologia para uma plataforma poderia aplicá-la a qualquer outra plataforma que ofereça suporte à manipulação no nível conceitual;

- o projeto e manipulação feitos no nível conceitual encontram-se mais próximos do projetista e mais distantes das especificações do ambiente de implementação;

- existem semânticas formais que dão sentido ao projeto e manipulação no nível conceitual. Portanto, este tipo de projeto está baseado em princípios matemáticos.

\section{Projeto de Distribuição de Dados}

Em um projeto de banco de dados centralizado, normalmente, o projetista cria o esquema global no nível conceitual, geralmente usando o ME-R; traduz esse esquema para o nível lógico, comumente para a linguagem do modelo relacional, e especifica os métodos de armazenamento físicos a serem utilizados, seguindo as três fases de projeto ilustradas na Figura 1. 
Em um projeto de banco de dados distribuído, o processo é praticamente o mesmo. A distribuição é realizada no nível lógico, antes da definição das estratégias do nível físico, e é realizada a partir de fragmentações aplicadas sobre o esquema lógico do banco de dados.

A fragmentação do banco de dados, como mencionado anteriormente, ocorre no nível lógico, a partir do seu esquema lógico, que após o processo de distribuição será composto pelos fragmentos resultantes da fragmentação. Após a geração do esquema lógico, e principalmente após sua fragmentação, o esquema conceitual é abandonado, tornando-se apenas uma documentação inicial da estrutura centralizada do banco de dados.

Em [6], os autores definem o esquema de fragmentação no modelo relacional como dependente das consultas feitas nos aplicativos de banco de dados. Isto nos fornece a impressão de que a fragmentação do banco de dados é acidental e dependente das aplicações existentes. Nosso trabalho pretende investigar o que há por trás desta visão "ad hoc".

\section{Comparações com a literatura}

Modelos conceituais para o projeto de dados para o projeto de dados vêm sendo desenvolvidos desde a proposta original de Chen [1]. Mais recentemente, procurou-se dar também a este modelo a possibilidade de manipular dados através de linguagens de consulta e manipulação (e.g. [5][10]), e existem implementações em que o projeto de dados (centralizado) e todos os acessos ao banco de dados são feitos apenas neste nível, como no projeto TEMPORA [7][8].

O método predominante na literatura para projeto de bancos de dados parte da fragmentação de relações no modelo relacional [4][6], operando transformações no esquema e instanciação no modelos chamadas de fragmentações borizontal, vertical, borizontal derivada e mista. Estas transformações são baseadas em consultas e as instanciações dos fragmentos devem obedecer a restrições que garantem sua corretude: completude, reconstrutibilidade e disjunção.

Similarmente, nosso trabalho irá transpor as transformações por fragmentação horizontal, vertical e mista para entidades do ME-R baseado em consultas ao ME-R. No entanto, precisaremos estender este conceito para lidar com hierarquias de classes de entidades, fragmentação derivada de relacionamentos, e a fragmentação derivada de classes de entidades através de caminhos no Diagrama E-R (DE-R). Preservaremos os critérios de 
corretude em todos os casos, garantindo completude, reconstrutibilidade e disjunção no nível conceitual.

Um trabalho na literatura que trata da transformação de DE-Rs é [2]. O objetivo das transformações, nesse caso, é o projeto do DE-R por meio de refinamentos sucessivos e as transformações são agrupadas em métodos de refinamento: top-down, bottom-up e misto. Estas transformações também devem obedecer a condições: correção e completude (que apesar da coincidência nominal, é um conceito distinto da completude da fragmentação). Diferentemente do nosso caso, as transformações dos refinamentos não são guiadas por consultas às instanciações do DE-R.

\section{Objetivos}

Este projeto de pesquisa visa a estudar formas de permitir o projeto de distribuição de dados a partir do modelo entidade-relacionamento (ER), que é apresentado com detalhes no capítulo 2. Ele engloba o projeto conceitual de um banco de dados global utilizando o modelo ER, que será posteriormente distribuído, e sua distribuição representada no seu esquema conceitual. É importante ressaltar que a fase do projeto físico não faz parte deste trabalho.

A partir da aplicação destas idéias no projeto de bancos de dados, o projeto de distribuição passa a ser composto de duas fases, em vez de três. A primeira fase, o projeto conceitual, produz o esquema conceitual, que além de suportar o esquema global do banco de dados, passa a suportar também o esquema de fragmentação, tornando-o parte ativa do banco de dados. E a segunda fase, o projeto físico, que não sofre nenhuma alteração.

Sob uma visão geral do projeto geral de um banco de dados, as fases de projeto permanecem as mesmas, porém a distribuição de dados que era realizada no nível lógico passa a ser representada no nível conceitual. As demais funções realizadas pelo nível lógico ainda permanecem, como, a manipulação de dados.

A ilustração da Figura 2 exibe o processo proposto acima. 


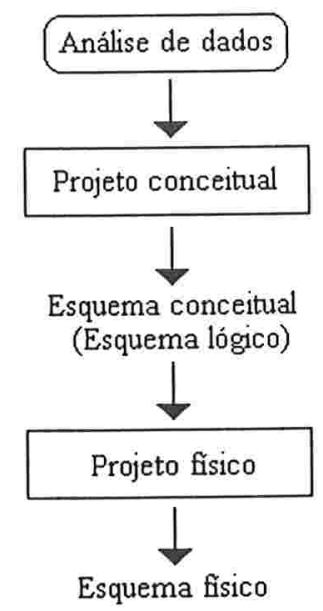

Figura 2: Fases de Projeto de um BD Conceitual

Este trabalho visa também a ressaltar que, ao contrário do que acontece no modelo relacional, a natureza do esquema de fragmentação é estrutural, e não acidental.

A distribuição do banco de dados é derivada da estrutura do grafo que representa o diagrama ER e não dependente de consultas realizadas por aplicativos de banco de dados. Tal consideração será apresentada durante as seções que oferecem a fragmentação no modelo ER (capítulo 6) e ressaltada na seção 7-2 do capítulo que conclui este projeto de pesquisa.

\section{Organização da Tese}

O capítulo 2 apresenta os elementos componentes do modelo ER, sobre o qual será realizado o projeto de distribuição de dados.

Para a representação de distribuição neste modelo, necessitamos de uma teoria básica sobre fragmentação de dados. Esta teoria, na literatura sobre bancos de dados distribuídos, encontra-se expressa em termos de um outro modelo, o modelo relacional de dados. Desta maneira, introduziremos a teoria sobre distribuição de dados (capítulo 3) segundo o modelo relacional, que será brevemente apresentado na seção 3-1.1.

Uma vez consolidados os conceitos sobre o modelo ER e fragmentação de dados (distribuição), dispomos de base teórica para procedermos à definição dos conceitos de fragmentação no modelo ER. 
Capítulo 1 - Introdução

A definição dos conceitos de fragmentação no modelo ER possui pré-requisitos, que incluem uma semântica de instanciação do modelo ER e uma linguagem de consultas ao modelo, que são explicados no capítulo 4.

Após a apresentação dos pré-requisitos necessários à introdução dos conceitos de distribuição no modelo ER (ME-R), introduzimos a fragmentação no diagrama ER no capítulo 5, onde são estabelecidos os princípios básicos para a fragmentação no ME-R.

O capítulo 6 apresenta a fragmentação derivada estrutural do modelo ER, decorrente dos conceitos básicos apresentados no capítulo 5, além de um exemplo final que compreende toda a teoria desenvolvida durante o texto.

O capítulo 7 descreve algumas conclusões e considerações importantes obtidas durante a realização deste projeto de pesquisa e o capítulo 8 apresenta as referências bibliográficas utilizadas neste trabalho. 
Capítulo 2

\section{O Modelo Entidade-Relacionamento}

"O modelo de dados entidade-relacionamento baseia-se na percepção de um universo constituído por um grupo básico de objetos chamados entidades e por relacionamentos entre estes objetos. Ele foi desenvolvido a fim de facilitar o projeto de bancos de dados permitindo a especificação de um esquema de empreendimento. Tal esquema representa a estrutura lógica global do banco de dados."

[4]

O Modelo Entidade-Relacionamento (ME-R) é o modelo de dados mais utilizado para o projeto conceitual de bancos de dados. O ME-R foi introduzido por Peter Chen em 1976 e, originalmente, o modelo incluía somente conceitos de classes de entidades, classes de relacionamentos e atributos, sendo que outros conceitos como atributos chaves e hierarquias de generalização foram adicionados, posteriormente, ao modelo inicialmente proposto.

\section{Conceitos do ME-R}

Introduziremos, agora, os conceitos do ME-R, seus elementos básicos e avançados, e daremos alguns exemplos sobre sua utilização. Na seção 2-1.1, discutiremos os conceitos inicialmente propostos por Chen e, na seção 2-1.2, os componentes do modelo avançado, adotando a divisão cronológica da construção do modelo sugerida em [2]. Alguns dos elementos pertencentes ao ME-R não serão discutidos devido à sua irrelevância para este projeto de pesquisa. O modelo completo pode ser encontrado em [2] ou em [3], além de outros.

\subsection{Elementos Básicos do ME-R}

Os elementos básicos que fazem parte do modelo são classes de entidades, classes de relacionamentos e atributos. 


\subsubsection{Classes de Entidades}

As classes de entidades, ou simplesmente entidades, representam classes de objetos no "mundo real" com existência independente. Uma entidade pode ser um objeto com existência física - uma pessoa, uma casa, ou um carro - ou pode ser um objeto com existência conceitual - uma empresa, um cargo, ou um curso. Entidades são graficamente representadas por meio de retângulos e são ilustradas no exemplo da Figura 3.

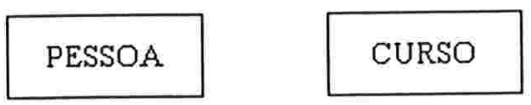

Figura 3: Entidades

\subsubsection{Classes de Relacionamentos}

As classes de relacionamentos, ou simplesmente relacionamentos, representam associações entre duas ou mais entidades e são representados graficamente através de losangos (ou diamantes). O número de entidades participantes em um relacionamento é chamado de grau do relacionamento. Um relacionamento de grau 2 é chamado de binário (mais comum), um de grau 3 é chamado de ternário. Relacionamentos com grau maior que 2 são também denominados relacionamentos $n$-ários, onde $n$ representa o número de classes de entidades envolvidas (Figura 4).

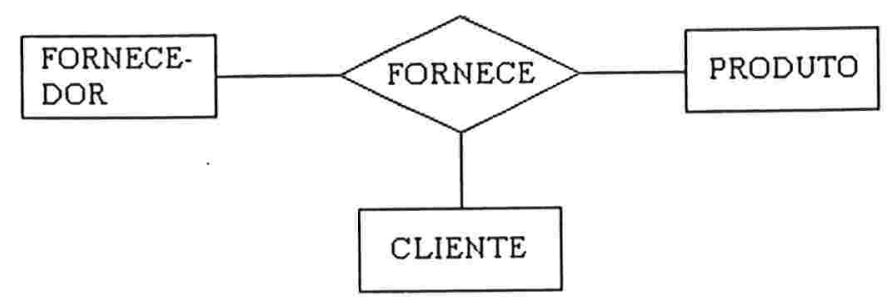

Figura 4: Relacionamento Ternário

Os relacionamentos binários que conectam uma entidade a ela mesma são chamados de auto-relacionamentos (Figura 5). A este tipo de relacionamento são adicionados rótulos à sua representação, para efeito de distinção entre os dois "papéis" que a entidade assume no relacionamento. 


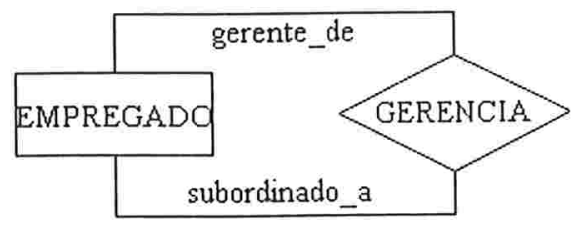

Figura 5: Auto-Relacionamento

Introduziremos, brevemente, o conceito de instanciação de classes de entidades e de classes de relacionamentos para definirmos as funções de cardinalidades, uma vez que a teoria sobre a instanciação do modelo ER será devidamente explicada na seção 4-2.

A instanciação de uma entidade ou um relacionamento é o conjunto de objetos pertencentes a estas classes. Por exemplo, as instâncias de uma classe de entidades EMPREGADO são conjuntos de informações sobre os indivíduos que pertencem a esta classe. As instâncias de um relacionamento são relações entre as instâncias das classes de entidades participantes desse relacionamento.

Relacionamentos são associados a funções de cardinalidades máximas e mínimas. As cardinalidades especificam o número de instâncias de um relacionamento das quais uma entidade pode participar. Se a existência da instância de uma entidade depende da sua participação em um relacionamento, a participação desta entidade em tal relacionamento é denominada total. Caso contrário, ela é denominada parcial. Por exemplo, consideremos a figura abaixo:

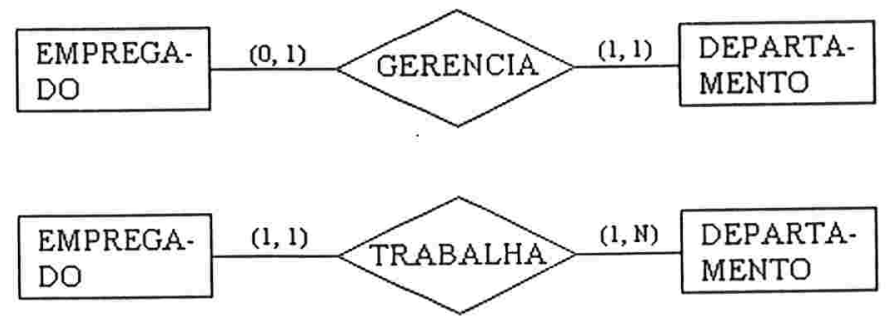

Figura 6: Cardinalidades

Podemos notar no exemplo da Figura 6 que a classe de entidades EMPREGADO possui par de cardinalidades $(0,1)$, significando que a participação de alguma(s) instância(s) de EMPREGADO pode(m) não acontecer no relacionamento GERENCLA, e que nenhuma instância desta entidade pode participar mais de uma vez deste relacionamento. 
Os relacionamentos podem ser interpretados de maneiras diferentes, dependendo das cardinalidades a ele atribuidas. Suponhamos no relacionamento GERENCIA (Figura 6), que um empregado pode gerenciar no máximo um departamento e que um departamento pode ser gerenciado por um empregado somente. Deste modo, baseado nas cardinalidades, GERENCIA é um relacionamento do tipo 1:1 (lê-se um-para-um) entre EMPREGADO e DEPARTAMENTO.

O relacionamento TRABALHA (Figura 6) entre EMPREGADO e DEPARTAMENTO é do tipo 1:N (lê-se um-para-muitos), desde que suponhamos que um empregado deve trabalhar somente para um departamento e que em um departamento trabalham muitos empregados. Porém, se admitirmos que um empregado pode trabalhar para vários departamentos, teremos o relacionamento TRABALHA (Figura 7) com tipo M:N (lê-se muitos-para-muitos).

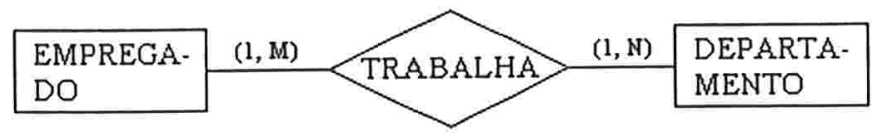

Figura 7: Relacionamento M:N

Outras representações gráficas utilizam linhas duplas incidentes no relacionamento para representarem participação total da entidade, e linhas simples incidentes no relacionamento para representarem participação parcial.

Nos exemplos acima, para o relacionamento TRABALHA (Figura 6 e Figura 7), admitimos que todo empregado deva trabalhar para no mínimo um departamento, assim, uma instância da entidade EMIPREGADO somente pode existir se esta participar em uma instância do relacionamento TRABALHA. A participação de EMPREGADO no relacionamento TRABALHA é chamada total, significando que toda instância da entidade EMPREGADO deve estar relacionada a uma instância da entidade DEPARTAMENTO através do relacionamento TRABALHA.

No relacionamento GERENCIA (Figura 6) não se admite que todo empregado gerencie um departamento, então a participação de EMPREGADO no relacionamento GERENCIA é parcial, ou seja, somente parte das instâncias da entidade EMPREGADO 
deve estar relacionada a uma instância da entidade DEPARTAMENTO através do relacionamento TRABALHA, mas não necessariamente todas.

\subsubsection{Atributos}

Atributos são propriedades particulares, ou elementares, de entidades ou relacionamentos que descrevem e carregam toda informação sobre estes objetos. Atributos podem ser adicionados ao esquema da Figura 4, resultando no esquema da Figura 8.

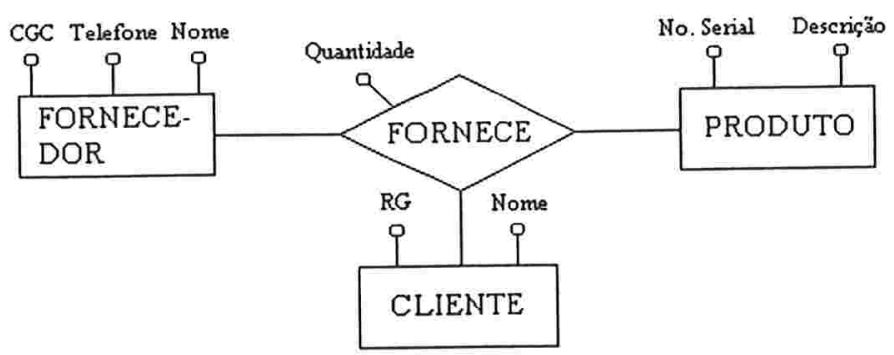

Figura 8: Atributos

Os atributos de FORNECEDOR são: CGC, Nome e Telefone, de PRODUTO são: No. Serial e Descrição, e de CLIENTE são: RG e Nome. O único atributo de FORNECE é Quantidade, representando a quantidade de produtos fornecidos pelo fornecedor ao cliente.

Os atributo são funções que aplicadas sobre as instâncias das entidades, ou relacionamentos, levam ao domínio do atributo. Por exemplo, o atributo CGC da entidade FORNECEDOR aplicado sobre uma determinada instância dessa entidade resulta em "123456789", que pertence ao domínio deste atributo.

Atributos podem ser mono-valorados, atributos que armazenam um único valor, ou multi-valorados, armazenando mais de um valor. Por exemplo, considerando a entidade FORNECEDOR, na Figura 8, CGC e Nome constituem uma amostra de atributos monovalorados, enquanto que o atributo Telefone pode ser multi-valorado, no caso de considerarmos que um mesmo fornecedor pode (e na maioria dos casos terá) mais de um número de telefone.

Cada atributo está associado a um domínio, isto é, um conjunto de valores válidos para aquele atributo. Um atributo simples (ou atômico) é um atributo que está definido sobre um único domínio. Na Figura 8, poderíamos especificar o conjunto de valores para o 
atributo Nome da entidade CLIENTE como sendo o conjunto de palavras formadas por caracteres do alfabeto separadas por caracteres em branco.

\subsection{Extensões Comuns ao ME-R}

Alguns dos elementos posteriormente adicionados à proposta inicial do modelo são bierarquia de generalização e atributos chaves.

\subsubsection{Hierarquia de Generalização}

Uma hierarquia de generalização é o resultado da união de dois ou mais conjuntos de entidades de nível mais baixo produzindo um conjunto de entidades de nível mais alto. [4]

Uma entidade $E$ é uma generalização de um grupo de entidades $E_{1}, E_{2}, \ldots, E_{n}$ se cada instância das classes $E_{1}, E_{2}, \ldots, E_{n}$ for também uma instância da classe $E$.

Segundo a propriedade fundamental de abstração de generalização, todas as propriedades da entidade (ou classe) genérica são herdadas pelas entidades generalizadas (subclasses). Em termos de ME-R, isto significa que todo atributo, relacionamento e generalização definidos para a entidade genérica são automaticamente herdados por todas as entidades generalizadas. Esta propriedade é muito importante, uma vez que permite a construção de hierarquias de generalização estruturadas.

A representação gráfica de uma generalização é dada por meio de um triângulo com uma seta incidente na entidade genérica e linhas conectando este triângulo às generalizações. Esta representação pode ser melhor compreendida através da Figura 9, onde as entidades CARRO, MOTOCICLETA e CAMINHÃO foram generalizadas para a entidade VEÍCULO. Nesta mesma figura, podemos analisar a herança de atributos, onde os atributos No. Cbassi, Cor e Ano Fabr. são atributos comuns a todas as entidades e, também, na qual cada entidade generalizada pode apresentar atributos privados ou exclusivos àquela entidade. 
Capítulo 2 - O Modelo Entidade-Relacionamento

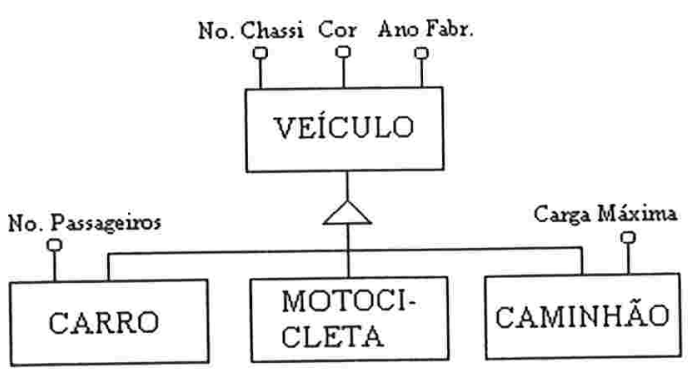

Figura 9: Hierarquia de Generalização Simples

As hierarquias de generalização são caracterizadas pelo tipo de cobertura que ela apresenta. A cobertura de uma generalização é total se cada instância da classe genérica é mapeada para ao menos uma instância das subclasses, e é parcial se existe alguma instância da classe genérica que não pode ser mapeada para nenhuma instância das subclasses.

As entidades generalizadas são necessariamente disjuntas. No exemplo da Figura 9, um carro não pode ser um caminhão nem uma motocicleta, e assim por diante. Algumas propostas na literatura consideram disjunção como uma propriedade de cobertura, como em [2], neste trabalho estaremos considerando somente a cobertura total ou parcial.

Para efeito de representação, quando a generalização possuir cobertura total o triângulo que a representa estará preenchido, e quando for parcial o triângulo estará vazio. Na Figura 10, podemos ver os dois tipos de cobertura de generalização.

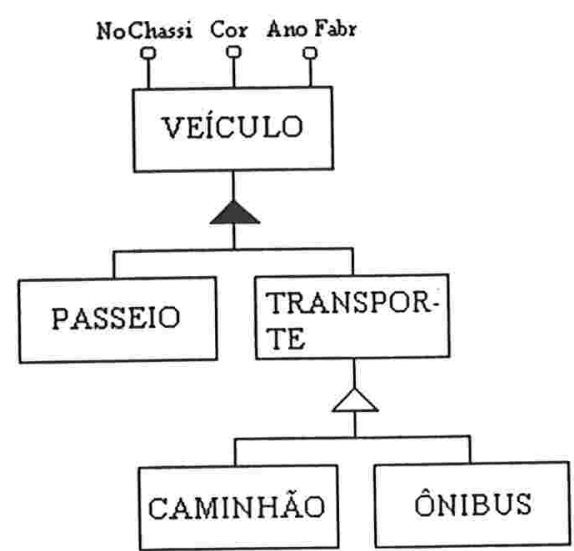

Figura 10: Hierarquia de Generalização Composta

Cada uma das instâncias da entidade genérica VEÍCULO é necessariamente mapeada para uma instância de uma das entidades PASSEIO ou TRANSPORTE, significando que um veículo pode ser exclusivamente de passeio ou de transporte. Já a 


\section{Capítulo 2 - O Modelo Entidade-Relacionamento}

entidade TRANSPORTE possui instância(s) que não são mapeadas para nenhuma instância das entidades CAMINHÄO ou ÔNIBUS, significando que um veículo de transporte não precisa ser necessariamente um ônibus ou caminhão, pode, por exemplo, ser um navio.

\subsubsection{Atributos Chaves}

Um atributo chave de uma entidade é um atributo (chave simples), ou um conjunto de atributos (chave composta), usado(s) para identificar unicamente uma instância dessa entidade. Uma chave deve ter um valor distinto para todas as instâncias da entidade. $\mathrm{Na}$ Figura 10, o atributo NoChassi é uma chave da entidade VEÍCULO, já que não podem existir veículos com o mesmo número de chassi.

No caso da chave ser um conjunto de atributos, os valores combinados desse conjunto de atributos também deverão apresentar valores distintos para todas as instâncias da entidade. Por exemplo, na Figura 11, a entidade TELEFONE tem como chave o conjunto de atributos $\{$ Cód. Pais, DDD, Número $\}$.

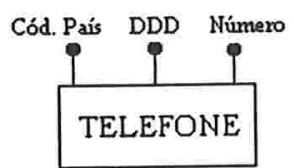

Figura 11: Identificadores

Para efeito de terminologia, chaves são também chamadas de chaves primárias.

A representação gráfica de um atributo chave é um círculo preenchido. No caso da chave ser composta, ela será formado pela combinação de todos os atributos que apresentem um círculo preenchido. (Figura 11)

Uma definição para chaves, segundo [2], é a que se $I$ é um atributo chave de uma entidade $E$ então:

(1) não pode haver duas instâncias de $E$ com o mesmo valor de chave;

(2) se retirarmos qualquer atributo $A_{i}$ da chave $I$, a propriedade (1) não mais será satisfeita. 
Capítulo 3

\section{Distribuição de Dados}

Nos últimos anos, o crescente aumento das redes de computadores em todo o mundo tem sido muito significante e vem refletindo seu impacto sobre as mais diversas áreas da computação.

O objetivo das redes de computadores é o compartilhamento de recursos e, principalmente, de informação entre seus usuários. A distribuição da informação se faz necessária para atender este tipo de tecnologia, o que nos conduz ao conceito de bancos de dados distribuidos.

Um banco de dados distribuído constitui-se de um banco de dados integrado construído sobre uma rede de computadores, ao invés de um único computador. Os dados que constituem o banco de dados estão armazenados em locais diferentes da rede de computadores, e os programas que são executados por estes computadores acessam os dados como se eles estivessem armazenados localmente; isto é chamado de transparência da distribuição.

\section{Arquitetura de Referência para Bancos de Dados Distribuídos}

Nesta seção, introduziremos uma arquitetura de referência para a distribuição de um banco de dados. Esta arquitetura, mostrada na Figura 12, é definida em termos do modelo relacional de dados em [6]. Seus três primeiros níveis serão devidamente explicados, uma vez que são independentes do SGBD (Sistema Gerenciador de Banco de Dados) utilizado, o que caracteriza a proposta deste projeto de pesquisa. 


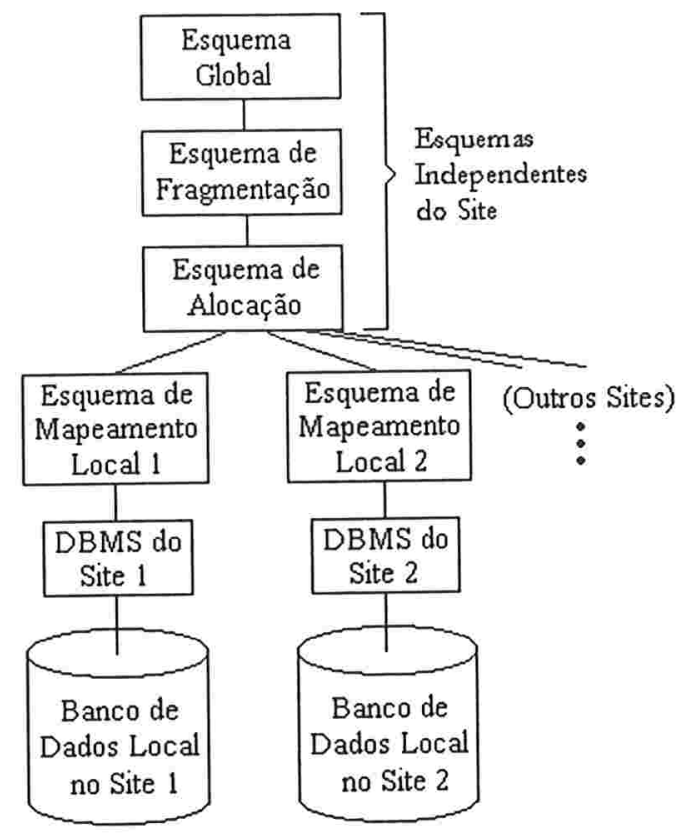

Figura 12: Arquitetura de Referência para Bancos de Dados Distribuídos

Esta arquitetura não é explicitamente implementada em todos os bancos de dados distribuídos, mas seus níveis são conceitualmente importantes no entendimento da organização de qualquer banco de dados distribuído.

O primeiro nível da arquitetura é o esquema global. O esquema global apresenta os dados, conceitualmente organizados segundo algum modelo de dados, exatamente como se eles estivessem em um esquema centralizado. Não existe nenhum tipo de distribuição neste nivel.

A partir do modelo relacional, o esquema global está constituído de um conjunto de relaçōes globais. Cada relação global pode ser dividida em diversas e exclusivas porções, chamadas de fragmentos. Existem algumas maneiras de efetuarmos a divisão das relações, as quais explicaremos nas próximas seções.

O mapeamento entre as relações globais e seus fragmentos é definido no esquema de fragmentação. Este mapeamento é do tipo um-para-muitos, pois um dado fragmento deve pertencer à, no máximo, uma relação global, enquanto que uma única relação global pode possuir vários fragmentos. Os fragmentos são representados na forma $R_{i}$ onde $\mathrm{R}$ é o nome da relação global e $i$ é um índice que distingue um dado fragmento dos demais, isto é, $R_{i}$ representa o i-ésimo fragmento da relação global $R$. 
Os fragmentos são porções lógicas de uma relação global que devem ser fisicamente armazenadas em um ou mais locais da rede de computadores. A alocação destes fragmentos está contida no esquema de alocação. A alocação de fragmentos deve considerar os casos em que o banco de dados é redundante, ou seja, há replicação de fragmentos, um ou mais locais da rede contendo um mesmo fragmento, ou uma cópia de fragmento. A representação usada para os fragmentos alocados por este esquema é $R_{i}^{j}$ e indica o i-ésimo fragmento da relação global $R$ alocado no local $j$.

Todos os fragmentos alocados em um dado local constituem a imagem fisica deste local. Os esquemas global, de fragmentação e alocação podem ser observados na Figura 13.

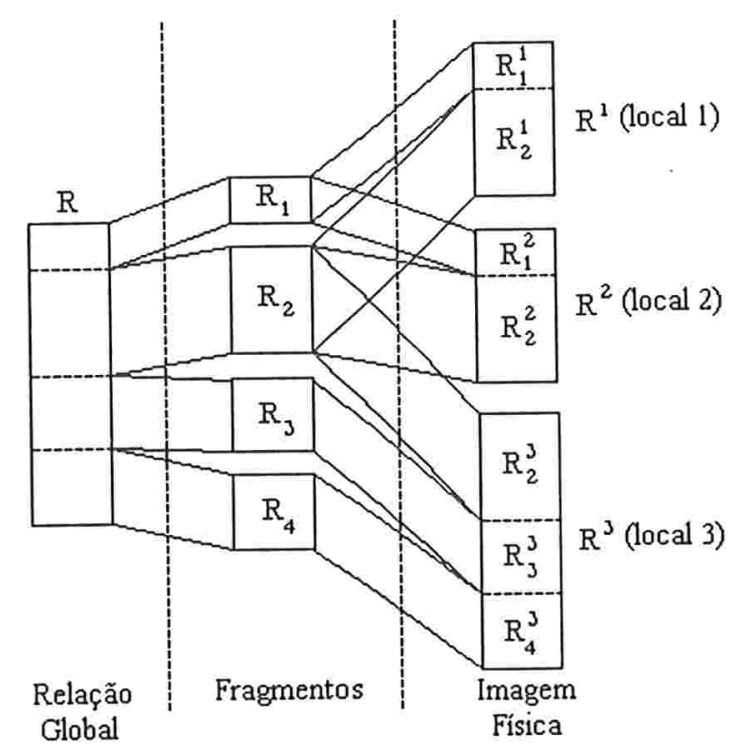

Figura 13: Fragmentos e Imagem Física para uma Relação Global

Para este projeto, estaremos considerando apenas os dois primeiros níveis desta arquitetura, o projeto conceitual global do banco de dados e seu esquema de fragmentaçào. O esquema de alocação dos fragmentos não é parte integrante deste projeto, porém, na seção 6-5, apresentaremos algumas noções de como a geração da imagem física dos fragmentos pode ser realizada.

\subsection{O Modelo Relacional de Dados}

Em bancos de dados relacionais, os dados são armazenados em tabelas, chamadas de relações. Estas relações são compostas por colunas e linhas. As colunas representam os 


\section{Capítulo 3 - Distribuição de Dados}

atributos e as linhas são denominadas tuplas. $O$ número de atributos em uma relação representa o grau desta relação e o número de tuplas sua cardinalidade.

A definição do modelo relacional considera uma relação como um conjunto de tuplas, de acordo com as seguintes propriedades:

(1) Não podem existir duas tuplas idênticas na mesma relação;

(2) Não há uma ordem definida entre as tuplas na relação.

A Figura 14 mostra a relação EMP (Empregado) constituída por quatro atributos NoEmpregado, Nome, Idade, NoDepartamento.

\begin{tabular}{|cccc|}
\hline NoEmpregado & Nome & Idade & NoDepartamento \\
\hline 3 & João & 34 & 2 \\
2 & José & 28 & 1 \\
5 & Manuel & 45 & 2 \\
15 & Joaquim & 44 & 2 \\
35 & Maria & 30 & 1 \\
\hline
\end{tabular}

Figura 14: Exemplo de Relação Global

O esquema da relação é representado pelo nome da relação e os nomes de seus atributos. Por exemplo, o esquema da relação EMP é

\section{EMP(NoEmpregado, Nome, Idade, NoDepartamento)}

A relação no exemplo da Figura 14 apresenta cinco tuplas, por exemplo, \{5, Manuel, $45,2\}$ é uma tupla desta relação. O grau da relação EMP é 4 e a cardinalidade é 5.

Para que seja possível efetuarmos operações com estas relações, utilizaremos a álgebra relacional, que toma uma ou duas relações como operandos e produz uma relação como resultado.

Mencionaremos agora as operações unárias e binárias da álgebra relacional, bem como sua notação. 
Unárias:

- operador seleção $S L_{F} R$, onde $R$ é uma relação e $F$ é uma fórmula que expressa uma seleção de predicados.

- operador projeção $P J_{\text {Atrib }} \mathrm{R}$, onde Atrib denota um subconjunto de atributos da relação $R$ a serem projetados na relação resultante.

\section{Binárias:}

- operador união $\mathrm{R} U N S$, onde $R$ e $S$ denotam relações (que devem possuir esquemas compativeis) a serem unidas.

- operador diferença $R D F S$, onde a relação $S$ é subtraída da relação $R$. As relações $\mathrm{R}$ e $S$ devem possuir esquemas compatíveis.

- operador produto cartesiano R PC S, onde a relação resultante é formada por todos os atributos de $R$ e $S$. Toda tupla de R é combinada com cada tupla de $S$.

- operador junção $R J N_{F} S$, onde $F$ é uma fórmula que expressa uma seleção de predicados entre as relações $R$ e $S$. A relação resultante inclui todos os atributos de $R$ e $S$, e todas as tuplas de $R$ e $S$ que satisfaçam $F$. O operador $J N$ é derivado de uma seleção $(S L)$ sobre um produto cartesiano $(P C)$ da seguinte maneira:

$$
R J N_{F} S=S L_{F}(R P C S) \text {. }
$$

- operador junção natural R NJN $S$, onde a relação resultante é formada por uma junção no qual todos os atributos com mesmo nome nas relações $R$ e $S$ são comparados. Uma vez que estes atributos têm nomes e valores iguais em todas as tuplas, apenas um dos atributos aparecerá no resultado.

- operador semi-junção $R S J_{F} S$, onde $F$ denota a mesma fórmula entre as relações $R$ e $S$ da junção. O operador $S J$ é derivado de uma projeção $(P J)$ sobre uma junção $(J N)$ da seguinte forma:

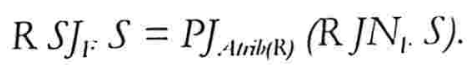

- operador semi-junção natural $R N S J_{1} S$, onde o resultado é obtido a partir de uma semi-junção $(S J)$ com a mesma fórmula $F$, como em uma junção natural $(N J N)$. 


\section{Fragmentação de Dados}

Na seção anterior, foi apresentada a arquitetura de referênci a para bancos de dados distribuídos, onde o segundo nível era o esquema de fragmentação. Neste esquema estão os tipos de fragmentação aplicados ao esquema global.

Existem dois tipos básicos de fragmentação de relações, a fragmentação horizontal e a fragmentação vertical. Primeiramente, discutiremos separadamente estes dois tipos de fragmentação, e então consideraremos fragmentações mais complexas que podem ser obtidas a partir da composição de ambas. Quando discutimos fragmentação, estamos nos referindo justamente a fragmentos e como estes fragmentos são definidos. Para a definição destes fragmentos utilizaremos a álgebra relacional discutida na seção 3-1.1, a qual recebe relações globais como operandos produzindo um fragmento como resultado.

$\mathrm{Na}$ definição dos fragmentos, segundo [6], existem algumas regras que devem ser seguidas:

(1) Completude - Todos os dados da relação global devem ser mapeados em fragmentos, isto é, um valor de atributo que pertence à relação global deve necessariamente pertencer a algum fragmento.

(2) Reconstrução - A reconstrução da relação global a partir de seus fragmentos deve ser sempre possível.

(3) Disjunção - Para evitar a redundância dos dados, exige-se que os fragmentos sejam disjuntos. Esta exigência faz mais sentido em se tratando de fragmentação horizontal, enquanto que na fragmentação vertical em algumas ocasiões a violação desta regra é permitida. As razões para esta violação serão discutidas quando abordarmos a fragmentação vertical.

\subsection{Fragmentação Horizontal}

A fragmentação horizontal consiste no particionamento das tuplas de uma relação global em subconjuntos. Estes subconjuntos são criados em consideração à necessidade de distribuição de uma relação quanto a características comuns apresentadas por porções 
independentes dentro desta relação. Por exemplo, particionamento quanto às características geográficas, visando à facilidade de gerenciamento e diminuição do banco de dados local. Consideremos a relação FORNECEDOR.

\section{FORNECEDOR(NoFomecedor, Nome, Cidade),}

um particionamento horizontal desta relação pode ser definido da seguinte maneira:

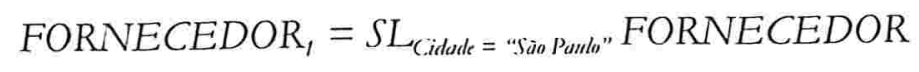

$$
\begin{aligned}
& F O R N E C E D O R_{2}=S L_{\text {Citlude }=\text { "Rio de Jautirim" }} \text { FORNECEDOR }
\end{aligned}
$$

Contudo, temos que garantir que as três regras discutidas na seção 3-2 sejam respeitadas.

Podemos verificar a completude desta fragmentação se, e somente se, "São Paulo" e "Rio de janeiro" forem os únicos dois valores possíveis para o atributo Cidade, caso contrário existiriam localidades que não estariam especificadas nesta fragmentação.

A regra de reconstrução é facilmente verificada, dado que a reconstrução da relação original é resultante da seguinte operação:

$$
\text { FORNECEDOR }=\text { FORNECEDOR, UN FORNECEDOR }{ }_{2}
$$

A verificação da regra de disjunção é trivial, visto que os predicados Cidade = "São Paulo" e Cidade = "Rio de Janeiro" são mutuamente exclusivos.

Os predicados utilizados na operação de seleção(SL) são chamados de qualificações dos fragmentos. Pelo exemplo acima, as qualificações para cada fragmento seriam:

$$
\begin{gathered}
q_{1}: \text { Cidade }=\text { "Sào Paulo" } \\
q_{2}: \text { Cidade }=\text { "Rio de Janeiro" }
\end{gathered}
$$

Assim, podemos concluir que para que a regra de completude se verifique, o conjunto de qualificaçōes para todos os fragmentos deve ser completo, ao menos em relação ao conjunto de valores permitidos. A condição de reconstrução é sempre verificada através 
da operação de união(UN), e a disjunção requer que as qualificações sejam mutuamente exclusivas.

\subsection{Fragmentação Vertical}

A fragmentação vertical de uma relação global é a subdivisão de seus atributos em grupos. Os fragmentos são obtidos projetando-se a relação global sobre cada um desses grupos.

A corretude da fragmentação depende da possibilidade de reconstrução da relação original e também da completude da operação, onde cada atributo deve ser mapeado em um ou mais atributos dos fragmentos, conforme as regras citadas na seção 3-2.

A fragmentação é realizada considerando-se que os atributos a serem agrupados têm características desejáveis em comum. Por exemplo, consideremos a relação global

\section{EMP(NoEmp, Nome, Salário, FGTS, NoGerente, NoDepart),}

onde estabeleceremos que salários e fundos de garantia serão tratados em separado dos demais atributos. Assim, uma fragmentação possível seria:

$$
\begin{aligned}
& E M P_{l}=P J_{\text {NaEmp, Nome, NoGernute, Nobepart }} E M P \\
& E M P_{2}=P J_{\text {NoEmp, Salirio, FGTS }} \text { EMP. }
\end{aligned}
$$

A reconstrução da relação original EMP pode ser obtida realizando-se uma junção natural entre os fragmentos, como se segue:

$$
E M P=E M P_{1} N^{\prime} N E M P_{2}
$$

Existem duas formas de garantir a reconstrução de uma relação global original após sua fragmentação. Uma delas é a inclusão da chave primária da relação global em todos os seus fragmentos, dessa forma a reconstrução se torna simples através de uma operação de junção entre os fragmentos. A outra maneira de se garantir a reconstrução é a geração de um determinante de tuplas que é usado de maneira semelhante a chaves automáticas de sistema e evita a replicação de chaves primárias muito grandes através dos fragmentos. 
Finalmente, consideremos o problema da disjunção dos fragmentos. Em geral, podese dizer que a motivação para a disjunção dos fragmentos na fragmentação vertical não é tão importante quanto na fragmentação horizontal. De fato, se em uma fragmentação vertical permitirmos que um mesmo atributo faça parte de dois ou mais fragmentos de uma relação global, é trivial a localização do dado replicado, pois sabe-se exatamente em que coluna ele se encontra. Todavia, se permitirmos que dois fragmentos horizontais se sobreponham, não é possível a referenciação direta da porção sobreposta.

\subsection{Fragmentação Mista}

A fragmentação mista é um tipo de fragmentação onde os fragmentos são resultantes da aplicação de operações de fragmentação sobre fragmentos, e não sobre relações globais. Estas operações podem ser aplicadas recursivamente, contanto que as regras de fragmentação sejam seguidas.

Utilizando a relação EMP da seção 3-2.2 e aplicando sobre seus fragmentos verticais $E M P_{1}$ e $E M P_{2}$ uma fragmentação horizontal produziremos uma fragmentação mista.

Seja a relação global

\section{EMP(NoEmp, Nome, Salário, FGTS, NoGerente, NoDepart)}

e seus fragmentos verticais

$$
\begin{gathered}
E M P_{1}=P J_{\text {Nollimp, Nome, NoGgerulte, NóDepart }} \text { EMP } \\
E M P_{2}=P J_{\text {NoEEmp, Sulinio, FGTS }} \text { EMP. }
\end{gathered}
$$

Aplicando-se uma fragmentação horizontal sobre estes fragmentos, teremos:

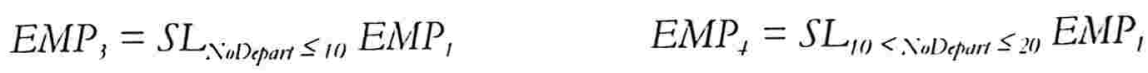

$$
\begin{aligned}
& E M P_{;}=S L_{\text {Niblepar }>20} E M P_{1},
\end{aligned}
$$

dos quais a relação global original pode ser perfeitamente reconstruida a partir da seguinte expressão: 
Capítulo 3 - Distribuição de Dados

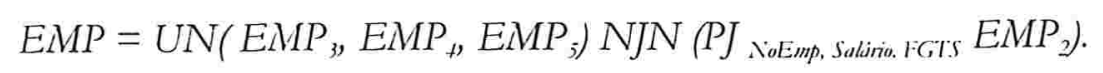

A fragmentação mista pode ser convenientemente representada através de uma árvore de fragmentação. Um exemplo de uma árvore de fragmentação pode ser visto na Figura 15.

A raiz da árvore corresponde à relação global original, as folhas correspondem aos fragmentos finais, e os nós intermediários correspondem aos fragmentos intermediários. $\mathrm{Na}$ Figura 15, a raiz (relação EMP) é verticalmente fragmentada em duas partes. Uma das partes constitui um nó folha, o fragmento $E M P_{2}$ desta árvore. A outra parte é fragmentada horizontalmente em três outras partes, produzindo outros três nós folhas, os fragmentos $E M P_{3}, E M P_{+}$e $E M P_{5}$.

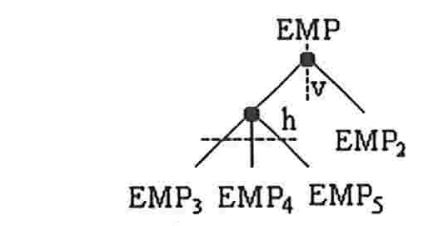

Figura 15: Árvore de Fragmentação

\subsection{Fragmentação Horizontal Derivada}

$\mathrm{Na}$ fragmentação horizontal vista na seção 3-2.1, a fragmentação de uma relação é realizada com base nas propriedades dos atributos desta relação. Em alguns casos, a fragmentação horizontal pode ser derivada de uma fragmentação horizontal de uma outra relação.

Para compreendermos melhor esta modalidade de fragmentação, consideremos a seguinte relação:

FORNECE(NoFornecedor, NoProduto, NoDepartamento, Quantidade).

Consideremos a relação FORNECEDOR da seção 3-2.1 e sua fragmentação em FORNECEDOR, e FORNECEDOR , onde cada fragmento contem as tuplas referentes a uma dada cidade. Assim, ao particionarmos a relação FORNECE, devemos considerar o fato de que os fragmentos devem conter as tuplas para fornecedores referentes a cada uma 
das cidades correspondentes. Todavia, a relação FORNECE não possui o atributo cidade, e sim a relação FORNECEDOR.

Desta forma, para determinarmos as tuplas de FORNECE que correspondem aos fornecedores em uma cidade, necessitamos de uma operação de semi-junção. Assim, a fragmentação derivada da relação FORNECE pode ser definida como:

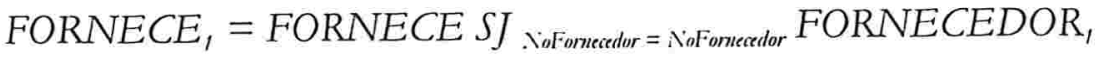

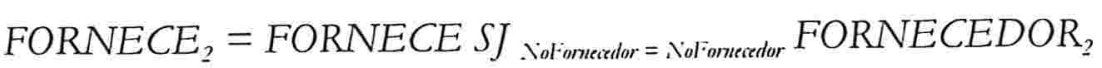

As operações de semi-junção acima selecionam as tuplas de FORNECE que se referem aos fornecedores em "São Paulo" e "Rio de Janeiro", respectivamente.

Os quantificadores para os fragmentos acima não podem ser definidos somente em função de atributos da relação FORNECE, uma vez que os fragmentos desta relação são derivados de outros fragmentos. Desta maneira, uma representação para estes quantificadores é:

$$
\begin{aligned}
& \text { q1: FORNECE.NoFornecedor = FORNECEDOR.NoFornecedor AND } \\
& \text { FORNECEDOR.Cidade = "São Paulo" } \\
& \text { q2: FORNECE.NoFornecedor = FORNECEDOR.NoFornecedor AND } \\
& \text { FORNECEDOR.Cidade = "Rio de Janeiro" }
\end{aligned}
$$

Notemos a presença de uma condição de existência na fragmentação realizada. Devemos assegurar que para cada tupla em FORNECE $E_{1}$, ou FORNECE , deve existir uma tupla em FORNECEDOR, ou FORNECEDOR 2 , com o mesmo valor para o atributo NoFornecedor.

A reconstrução da relação original pode ser realizada facilmente através de uma operação de união $(U N)$ entre os fragmentos.

A completude da fragmentação exige que não existam fornecedores em FORNECE que não pertençam a FORNECEDOR. Esta restrição de integridade em bancos de dados é denominada restrição de integridade referencial.

A condição de disjunção é satisfeita se uma tupla de FORNECE não corresponder a duas tuplas da relação FORNECEDOR que pertençam a fragmentos diferentes. 
Capítulo 4

\section{Pré-Requisitos à Fragmentação no ME-R}

Dentre a variedade de modelos sendo usados para a descrição e manipulação de dados com um sistema gerenciador de banco de dados, o modelo entidade-relacionamento é, sem dúvida, o representante mais popular dos modelos semânticos.

Desde o primeiro modelo proposto por Chen [1], muitos dos trabalhos de pesquisa sobre o ME-R empregaram-no como uma ferramenta de projeto devido ao seu poder descritivo, que certamente representou um enorme avanço em respeito à semântica pobre do modelo relacional.

$\mathrm{O}$ intuito da introdução de fragmentação ao ME-R é justamente estender este conceito de mera ferramenta de projeto que acompanha este modelo há tanto tempo. A representação de fragmentação no ME-R ressalta que a tarefa de distribuição de um banco de dados é decorrente da estrutura dos dados e não apenas decorrente de consultas de uma aplicação, como visto anteriormente na fragmentação no modelo relacional.

Este capítulo se destina a formalizar uma base teórica para a introdução da fragmentação ao modelo entidade-relacionamento.

\section{Modelo Relacional versus Modelo ER}

O projeto de um banco de dados, seja ele distribuído ou não, está longe de ser uma tarefa trivial.

As relações (do modelo relacional) constituem um modo homogêneo de representar informação, mas a parte do mundo real a ser modelada tende a ser uma coleção, muito pouco homogênea, de objetos que interagem. Desta maneira, precisamos de estruturas que sejam melhores abstrações, em vez de simples relações, o que nos conduz ao modelo entidade-relacionamento.

Considerando a teoria referente à distribuição de um banco de dados sobre o modelo relacional, estabeleceremos uma analogia entre estes dois modelos de dados a fim de validarmos as regras básicas de fragmentação de dados, mencionadas na seção 3-2, desta vez 
em relação ao ME-R. Discutiremos estas regras à medida que o conceito sobre a fragmentação no modelo entidade-relacionamento for sendo apresentada.

No modelo relacional, uma operação de fragmentação aplicada sobre uma relação global produz outras relações, assim, nada mais intuitivo que deduzirmos que a fragmentação de uma classe de entidades deva produzir outras classes de entidades. Além do mais, a fragmentação de um conjunto de relações no modelo relacional produz um outro conjunto de relações, agora fragmentos. Desta maneira, podemos imaginar que, ao fragmentarmos um diagrama ER, ou parte dele, produziremos um outro diagrama ER que representa o esquema de um banco de dados distribuído.

Como visto anteriormente, as fragmentações horizontais no modelo relacional são formadas por predicados (qualificações) associados às relações que resultam na divisão desta relação em novas relações. Estes predicados são parte de uma linguagem de consulta sobre o modelo em questão, que atuam sobre as tuplas (instâncias) das relações produzindo os fragmentos.

Da mesma maneira, para fragmentarmos o ME-R, também precisaremos da aplicação de consultas sobre o esquema do banco de dados. A fragmentação do modelo entidade-relacionamento deve atuar sobre instanciações do diagrama ER. Começamos, portanto, definindo o significado de instanciação.

\section{Instanciação no ME-R}

Cada elemento do ME-R será semanticamente instanciado através da função $I$ que representa uma instância de todo o diagrama ER. Seja $I D=\left\{i d_{1}, i d_{2}, \ldots, i d_{n}\right\}$ um conjunto contável de identificadores e $D E R=\{E, A, R, H, C\}$, um diagrama formado por todos os elementos pertencentes ao ME-R, onde
E: conjunto de classes de entidades;
A: conjunto de atributos;
$\mathrm{R}$ : conjunto de classes de relacionamentos;
$H$ : conjunto de hierarquias de generalização;
C: função de configuração do diagrama de acordo com: 
Capítulo 4 - Pré-Requisitos à Fragmentação no ME-R

- para cada entidade $e \in E, C(e)=\left\langle A_{w} A_{n d}\right\rangle$, onde $A_{d} \subseteq A$ corresponde ao conjunto de atributos chaves de $e$, e $A_{n d} \subseteq A$ ao conjunto de atributos não-chaves de $e$.

- para cada relacionamento $r \in \mathrm{R}, C(r)=\left\langle e_{1}, e_{2}, c_{12}, c_{21}\right\rangle$, onde $c_{12}$ e $c_{21}$ correspondem às restrições de cardinalidade.

- para cada hierarquia de generalização $b \in H, C(b)=\left\langle e,\left\{e_{i}\right\}\right.$, tipo $\rangle$, onde $e \in$ $E$ corresponde à classe de entidades "pai" da hierarquia, $\left\{e_{i}\right\} \subseteq E$ corresponde ao conjunto de "filhos" e tipo indica se a hierarquia é total ou parcial.

\subsection{Classes de Entidades}

O elemento básico do diagrama é a classe de entidades. Se $I$ é uma instância de todo o diagrama ER e $e$ é uma classe de entidades nessa instância, $I(e)$ representa a instância desta classe de entidades. Uma instância de uma classe de entidades $I(e)$ é um conjunto finito de identificadores (ou entidades), isto é,

$I(e)$ é um conjunto finito $\left\{i d_{i}\right\}, \operatorname{com} i d_{i} \in I D$.

\subsection{Atributos}

As classes de entidades são associadas a atributos, e cada a tributo atrib está associado a um certo domínio dom(atrib). A instanciação de um atributo é uma função sobre um conjunto de identificadores em seu domínio, isto é,

$I($ atrib) $: I D \rightarrow \operatorname{dom}($ atrib)

Para os atributos conectados a identificadores de uma classe de entidades $e$ temos,

$I($ atrib $): I(e) \rightarrow$ dom(atrib)

Se $I(e)=\{i d\} \Rightarrow I($ atrib $)(i d)=\left\{a_{1}, a_{2}, \ldots, a_{u}\right\}$, onde $a_{i} \in \operatorname{dom}($ atrib) para $0 \leq i \leq n$. 
Capítulo 4 - Pré-Requisitos à Fragmentação no ME-R

\subsection{Classes de Relacionamentos}

A instanciação de uma classe de relacionamento conectando classes de entidades contém um subconjunto de $n$-uplas formado a partir das instâncias das classes de entidades. Formalmente, se $r$ é uma classe de relacionamentos entre duas ou mais entidades $e_{1}, e_{2}, \ldots, e_{n}, I$ é uma instância do diagrama ER, então, $I(r)$ é um conjunto de $n$-uplas da forma:

$\left\langle i d_{1}, i d_{2}, \ldots, i d_{n}\right\rangle \in I(r)$, onde $\left\{i d_{1}\right\} \in I\left(e_{1}\right),\left\{i d_{2}\right\} \in I\left(e_{2}\right), \ldots,\left\{i d_{n}\right\} \in I\left(e_{n}\right)$, restritas às restrições de cardinalidade.

\subsection{Hierarquias de Generalização}

A instanciação de uma hierarquia de generalização que tem $e$ como classe de entidades "pai" e o conjunto $\left\{e_{i}\right\}$ como classes de entidades "filhos", sendo $I$ uma instância do diagrama ER obedece às seguintes restrições:

$$
\begin{aligned}
& I\left(e_{i}\right) \subseteq I(e), \quad \text { para } i=1,2, \ldots, n . \\
& I\left(e_{i}\right) \cap I\left(e_{j}\right)=\varnothing \text { para } i \neq j .
\end{aligned}
$$

No caso de hierarquia total, então:

$$
I(e)=I\left(e_{1}\right) \cup I\left(e_{2}\right) \cup \ldots \cup I\left(e_{11}\right) .
$$

No caso de hierarquia parcial, então:

$$
I(e) \supseteq I\left(e_{1}\right) \cup I\left(e_{2}\right) \cup \ldots \cup I\left(e_{11}\right) .
$$

\section{Linguagem de Consulta ao ME-R}

A fragmentação de um banco de dados requer que consultas sejam efetuadas sobre o seu esquema conceitual. Conforme visto na seção 3-2, a álgebra relacional foi a linguagem utilizada para a fragmentação das relações que compõem um esquema relacional de dados.

No modelo entidade-relacionamento, várias linguagem de consulta e manipulação de dados foram propostas, como a linguagem GORDAS apresentada em [3], além de outras, como em [5], [12] e [13]. Baseando-nos nestas linguagens propostas, optamos por utilizar um 
tipo semelhante de linguagem de consulta ao qual denominamos Linguagem de Definição de Caminbos.

Esta linguagem utiliza-se da estrutura do grafo que representa um diagrama ER para a especificação de um caminho no grafo. Tal caminho é formado pelos elementos que compōem um diagrama ER (seções 2-1.1 e 2-1.2).

Um caminho no grafo pode ser classificado segundo o número de classes de entidades, ou hierarquias, que ele contém. Os nós que compõem estes caminhos podem conter restrições, que podem ser vazias ou não. Restrições são composições lógicas formadas por predicados sobre os atributos, sejam eles pertencentes a classes de entidades, classes de relacionamentos ou hierarquias de generalização.

Para a especificação desta linguagem, nas próximas seções, utilizaremos o diagrama apresentado na Figura 16 como exemplo.

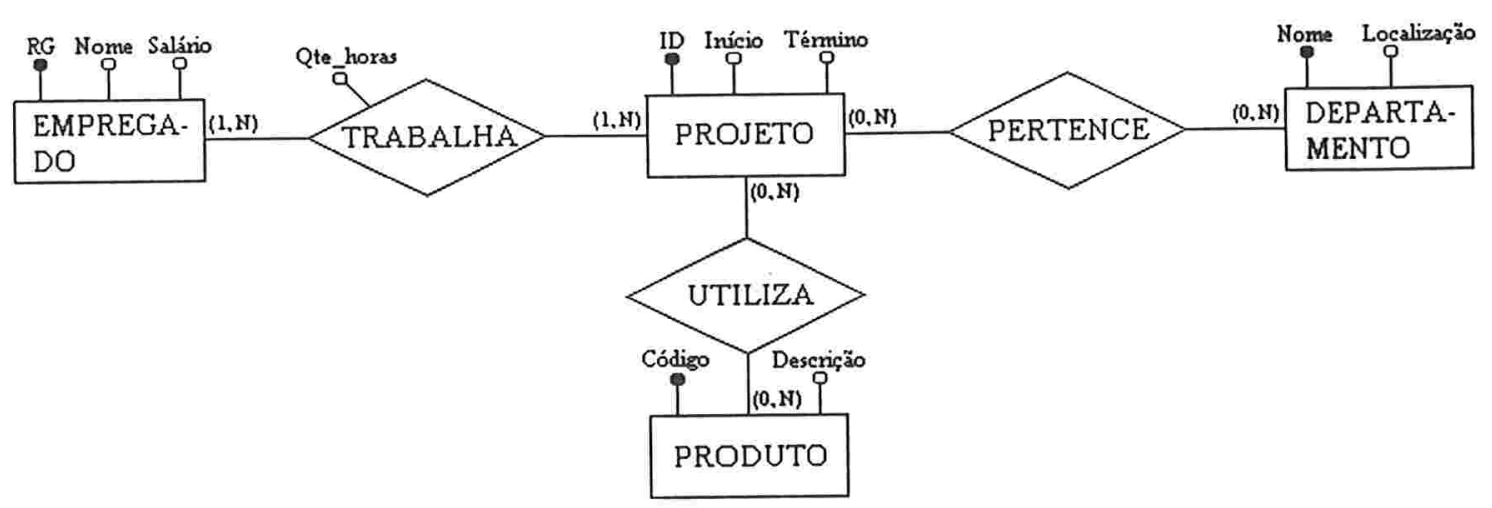

Figura 16: Diagrama ER

\subsection{Caminhos Unários}

Os caminhos unários são compostos apenas por uma classe de entidades, ou hierarquia. Seja $e$ uma classe de entidades ou hierarquia, e $r$ uma restrição sobre os atributos de $e$, um caminho unário apresenta-se na forma: e.r.

Para melhor ilustrarmos a definição apresentada acima, consideremos o diagrama da Figura 16. Uma consulta de caminho unário sobre este diagrama pode ser:

"Forneça todos os empregados que possuem salário superior a 500,00", 
Capítulo 4 - Pré-Requisitos à Fragmentação no ME-R

que resulta em:

EMPREGADO.Salário > 500,00.

Uma outra consulta de caminho unário pode ser:

"Forneça todos os empregados que possuem salário superior a 500,00 e inferior a 1.000,00",

que resulta no caminho:

EMPREGADO. $\{$ Salário $>500,00$ and Salário $<1.000,00\}$.

Vale notar que a primeira consulta produziu um caminho com restrição simples, enquanto que a segunda produziu um caminho com restrição composta, utilizando-se de chaves e do operador lógico and na sua formação.

\subsection{Caminhos Binários}

Os caminhos são compostos por duas classes de entidades e/ou hierarquias. Sejam $e_{\text {, }}$ e $e_{2}$ classes de entidades e/ou hierarquias, seja $\mathrm{R}_{12}$ uma classe de relacionamentos entre $e_{1}$ e $e_{2}$, e sejam $r_{1}, r_{2}$ e $r_{12}$ restrições sobre os atributos de $e_{1}, e_{2}$ e $R_{12}$, respectivamente. Um caminho binário apresenta-se na forma: $e_{1} \cdot r_{1} \mathrm{R}_{12} \cdot r_{12} e_{2} \cdot r_{2}$.

Considerando o diagrama da Figura 16, uma consulta de caminho binário pode ser:

"Forneça todos os empregados que possuem salário superior a 500,00 e trabalbam no projeto número 5",

que produz:

EMPREGADO.Salário > 500,00 TRABALHA PROJETO.Id=5.

Uma outra consulta de caminho binário pode ser: 
Capítulo 4 - Pré-Requisitos à Fragmentação no ME-R

"Forneça todos os empregados que possuem salário superior a 500,00 e trabalharam pelo menos 10 horas no projeto nimero 5",

que produz:

EMPREGADO.Salário > 500,00 TRABALHA.Qte_horas $\geq 10$ PROJETO.Id $=5$.

\subsection{Caminhos $\mathrm{N}$-ários}

Os caminhos n-ários são compostos por $n$ classes de entidades e/ou hierarquias de generalização. Generalizando as definições de caminhos unários e binários apresentadas nas últimas duas seções, sejam $e_{l}, e_{2}, \ldots, e_{n}$ classes de entidades e/ou hierarquias, sejam $R_{12}, R_{23}, \ldots$, $\mathrm{R}_{n-l, ~}$ classes de relacionamentos entre $e_{1}$ e $e_{2}, e_{2}$ e $e_{3}, \ldots, e_{n-l}$ e $e_{n}$, respectivamente, e sejam $r_{1}, r_{2}$, $\ldots, r_{11}, r_{12}, r_{23}, \ldots, r_{n-1}$ "restrições sobre os atributos de $e_{l}, e_{2}, \ldots, e_{n}, \mathrm{R}_{12}, \mathrm{R}_{23}, \ldots, \mathrm{R}_{n-1}$, respectivamente. Um caminho n-ário apresenta-se na forma: $e_{1} \cdot r_{1} R_{12} \cdot r_{12} e_{2} \cdot r_{2} R_{23} \cdot r_{23} e_{3} \cdot r_{3} \ldots R_{n-1}$ ${ }_{n} r_{n-l n} e_{n} \cdot r_{n}$.

De acordo com o diagrama da Figura 16, uma consulta de caminho n-ário pode ser:

"Forneça todos os empregados que possuem salário superior a 500,00 e trabalbam em algum projeto do departamento de R.H.",

que resulta em:

EMPREGADO.Salário > 500,00 TRABALHA PROJETO PERTENCE DEPARTAMENTO.Nome = 'R.H.".

Uma outra consulta de caminho n-ário um pouco mais complexa pode ser:

"Formeça todos os empregados que possuem salário superior a 500,00 que trabalbam em algum projeto que utilize o produto "X" e que pertença ao departamento de R.H.", 
Capítulo 4 - Pré-Requisitos à Fragmentação no ME-R

que resulta em:

EMPREGADO.Salário > 500,00 TRABALHA PROJETO/UTILIZA PRODLTO.Descrição = " $X$ " and PERTENCE DEPARTAMENTO.Nome = "R.H."].

Vale ressaltar a utilização de colchetes e do operador lógico and na segunda consulta, uma vez que o caminho resultante compreende um sub-caminho composto na sua formação (PROJETO/UTILIZA PRODUTO.Descrição $=$ ' $X$ " and PERTENCE DEPARTAMENTO.Nome = "R.H.") e não um caminho simples, como visto nas demais consultas.

Diante dos conceitos apresentados até agora, dispomos de uma base teórica para iniciarmos as definições de fragmentação no modelo ER. O próximo capítulo fornece as diretrizes primárias para a introdução da fragmentação. 
Capitulo 5

\section{Fragmentação Primária do Diagrama ER}

A teoria apresentada neste capítulo fundamenta-se nos elementos do modelo entidade-relacionamento, tomados separadamente, para a introdução dos conceitos básicos sobre a fragmentação no ME-R. A fragmentação de um diagrama ER completo, ou seja, com relacionamentos entre diversas entidades, é tratada no próximo capítulo.

A idéia principal da fragmentação do diagrama enti dade-relacionamento é a aplicação de consultas sobre seus elementos, utilizando-se da linguagem de definição de caminhos apresentada na seção 4-3, de forma análoga à fragmentação no modelo relacional (seção 3-2).

Um aspecto importante quando tratamos de fragmentação de um diagrama ER é a associação entre o diagrama original e o diagrama fragmentado. No decorrer deste capítulo, durante a fragmentação de cada elemento do ME-R, apresentaremos a associação implícita existente entre os elementos de cada um destes diagramas. Tal associação permite a reconstrução do diagrama original a partir do diagrama fragmentado.

Primeiramente, analisaremos os tipos de fragmentação aplicados sobre as classes de entidades. A partir do conceito de fragmentação de classes de entidades, analisaremos os tipos de fragmentação aplicados sobre hierarquias de generalização e analisaremos os efeitos de uma operação de fragmentação sobre um elemento que participe de um autorelacionamento.

Antes de iniciarmos os conceitos sobre fragmentação dos elementos do modelo ER, introduziremos duas operações, as operação de união e agregação, que são necessárias para que as fragmentações obedeçam às três regras apresentadas na seção 3-2.

\section{União e Agregação}

Como mencionado anteriormente, as fragmentações devem obedecer às três regras básicas que são: completude, reconstrução e disjunção. As regras de completude e disjunção são facilmente verificadas através da análise dos fragmentos em relaçào ao elemento original. 


\section{Capítulo 5 - Fragmentação Primária do Diagrama ER}

A regra da reconstrução, todavia, necessita de uma função que realmente una os fragmentos a fim de obter o elemento original.

No caso da fragmentação horizontal, os fragmentos resultantes possuem o mesmo esquema do elemento inicial, portanto, necessitamos de uma função que combine as instâncias de cada um dos fragmentos, reconstruindo o elemento fragmentado.

Definiremos a função de união dos fragmentos segundo a semântica apresentada na seção 4-2. Seja $E$ uma classe de entidades (hierarquia) $\operatorname{com} I(E)=\left\{i d_{1}, i d_{2}, \ldots, i d_{n}\right\}$ seu conjunto finito de identificadores (instâncias). Após uma fragmentação horizontal aplicada sobre $E$, foram produzidos os seguintes fragmentos com seus respectivos conjuntos de identificadores, $E_{1} \operatorname{com} I\left(E_{1}\right)=\left\{i d_{1}, i d_{2}, \ldots, i d_{s}\right\}, E_{2} \operatorname{com} I\left(E_{2}\right)=\left\{i d_{s+1}, i d_{s}+_{2}, \ldots, i d_{r}\right\}, \ldots, E_{l}$ com $I(E)=\left\{i d_{r+1}, i d_{r+2}, \ldots, i d_{n}\right\}$, com as regras de completude e disjunção devidamente respeitadas.

A função $U n$ é definida como sendo o conjunto união entre as instâncias de cada um dos fragmentos, ou seja,

$$
\begin{gathered}
\left.U_{n}=I\left(E_{1}\right) U I\left(E_{2}\right) U \ldots U I(E)\right\}=\left\{i d_{1}, i d_{2}, \ldots, i d_{n}, i d_{s+1}, i d_{s+2}, \ldots, i d_{1}, i d_{r+1}, i d_{r+2}, \ldots, i d_{n}\right\} . \\
U n=I(E)=\left\{i d_{1}, i d_{2}, \ldots, i d_{n}\right\} .
\end{gathered}
$$

No caso da fragmentação vertical, os fragmentos resultantes não possuem o mesmo esquema do elemento inicial, mas possuem seus esquemas individuais como subconjuntos do esquema do elemento fragmentado, além dos mesmos identificadores que o instanciavam. Por isso, necessitamos de uma função que realize a agregação dos fragmentos, levando em consideração a associação implícita existente entre os fragmentos, que será discutida na seção 5-2.2.

Definiremos a função de agregação de acordo com a semântica discutida na seção 42. Seja $E$ uma classe de entidades (hierarquia) $\operatorname{com} I(E)=\left\{i d_{1}, i d_{2}, \ldots, i d_{n}\right\}$ seu conjunto finito de identificadores (instâncias). Após uma fragmentação vertical aplicada sobre $E$, foram produzidos os fragmentos $E_{l}, E_{2}, \ldots, E_{m} \operatorname{com} I\left(E_{l}\right)=I\left(E_{2}\right)=\ldots=I\left(E_{m}\right)=\left\{i d_{1}, i d_{2}, \ldots, i d_{n}\right\}$.

Admitamos que o conjunto finito dos atributos de $E$ seja $\left\{k_{1}, k_{2}, \ldots, k_{1}, a_{1}, a_{2}, \ldots, a_{r}\right\}$, sendo $k_{i}$ os atributos chaves de $E$ para $1 \leq i \leq s$, e $a_{i}$ os atributos não-chaves de $E$ para $1 \leq i \leq$ 


\section{Capítulo 5 - Fragmentação Primária do Diagrama ER}

r. Dessa maneira, o conjunto de atributos dos fragmentos será da forma $E_{j}=\left\{k_{1}, k_{2}, \ldots, k_{1}\right\}$ $U A_{j}$, sendo $A_{j} \subseteq\left\{a_{1}, a_{2}, \ldots, a_{r}\right\}$, para $1 \leq j \leq m$.

A função de agregação reconstruirá o elemento fragmentado a partir da geração de uma nova classe de entidades (hierarquia) com seu conjunto de atributos formado através da união entre os subconjuntos de atributos dos fragmentos, além dos atributos chaves comuns a todos os fragmentos, ou seja,

$$
A g=\left\{k_{1}, k_{2}, \ldots, k_{3}\right\} U A_{1} U A_{2} U \ldots U A_{1 n}=\left\{k_{1}, k_{2}, \ldots, k_{2}, a_{1}, a_{2}, \ldots, a_{r}\right\}
$$

\section{Fragmentação de Classes de Entidades}

Nesta seção, a fragmentação de classes de entidades, ou simplesmente entidades, será abordada utilizando-se um diagrama ER composto apenas por entidades, isto é, sem relacionamentos com outras entidades.

A fragmentação de entidades é formada por dois tipos básicos: a fragmentação horizontal e a fragmentação vertical. Ambos os tipos de fragmentação produzem novas classes de entidades. Porém, o que as difere da classe de entidades original é a incorporação de predicados no caso da fragmentação horizontal, e o esquema da classe da entidade no caso da fragmentação vertical.

Discutiremos cada um dos tipos de fragmentação de entidades nas duas próximas seções.

\subsection{Fragmentação Horizontal de Classes de Entidades}

A fragmentação horizontal de entidades consiste no particionamento do conjunto de identificadores que instanciam uma entidade original em subconjuntos de identificadores que instanciam os fragmentos. Este particionamento é realizado a partir de consultas geradas sobre o esquema da classe de acordo com algum critério desejado que pode ser, por exemplo, geográfico.

Para definirmos a fragmentação horizontal de entidades acrescentamos uma nova propriedade sintática à classe de entidades que chamaremos de conjunto embutido de restrições, ou simplesmente restrições. Estas restrições são combinações booleanas de 
predicados que associadas à classe de entidades atuam como um "filtro" para as suas instâncias, caracterizando, assim, as instâncias dessa entidade em relação aos seus atributos.

Uma classe de entidades em seu estado original possui um conjunto vazio de restrições e, por isso, contém todas as instâncias possíveis àquela classe.

A aplicação de uma consulta de fragmentação sobre uma entidade produz outras entidades com o mesmo esquema da entidade original, a não ser por uma diferença, a incorporação de restrições por parte das novas entidades. A incorporação destas restrições pelas novas entidades é realizada a partir da conjunção booleana (AND) das restrições anteriormente pertencentes à classe de entidades de origem com as novas restrições impostas pela fragmentação propriamente dita.

A Figura 17 exibe um exemplo de fragmentação horizontal segundo um critério geográfico, gerando duas outras classes de entidades, agora fragmentos, a partir da entidade original.

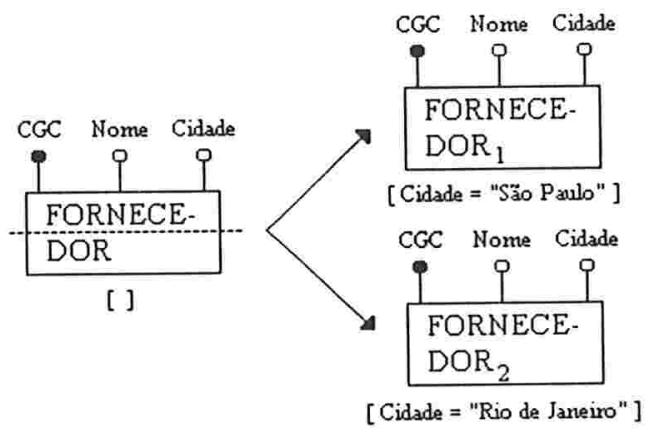

Figura 17: Fragmentação Horizontal de Classes de Entidades

Às entidades FORNECEDOR, e FORNECEDOR, foram atribuídas as restrições [Cidade = "São Paulo'] e [Cidade = 'Rio de Janeiro'], respectivamente. Neste caso, a conjunção das restrições não é explícita, pois a entidade de origem (FORNECEDOR) possuía um conjunto vazio de restrições.

A associação existente entre a entidade de origem e as novas entidades neste tipo de fragmentação corresponde à uma hierarquia de generalização total implícita, onde a entidade de origem representa a entidade "pai" dessa hierarquia e as novas entidades representam as entidades "filhas", conforme a Figura 18. 


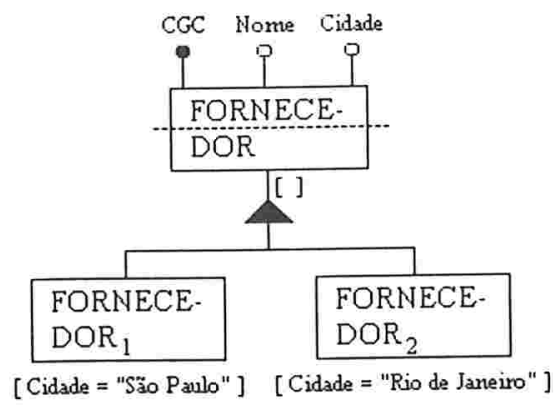

Figura 18: Associação Implícita entre Diagramas (Frag. Horizontal Entidades)

Para garantirmos que as três regras básicas de fragmentação, mencionadas anteriormente, sejam válidas para este tipo de fragmentação, analisaremos uma a uma.

Podemos verificar a completude desta fragmentação se, e somente se, "São Paulo" e "Rio de Janeiro" forem os únicos dois valores possíveis para o atributo Cidade, caso contrário existiriam localidades que não estariam especificadas nesta fragmentação.

A regra de reconstrução é facilmente verificada, dado que a reconstrução da classe de entidades original é facilmente alcançada através de uma operação de união entre os conjuntos de restrições que caracterizam cada um dos fragmentos.

A verificação da regra de disjunção é trivial, visto que as restrições [Cidade = "São Paulo'] e [Cidade = 'Rio de Janeiro'] são mutuamente exclusivos.

\subsection{Fragmentação Vertical de Classes de Entidades}

A fragmentação vertical de classes de entidades consiste no particionamento do conjunto de atributos que caracterizam uma classe de entidades de origem em subconjuntos de atributos que caracterizam os fragmentos. Neste particionamento, são produzidas novas classes de entidades com o esquema composto por estes subconjuntos de atributos da classe original, onde cada uma dessas novas classes contém, necessariamente, os atributos chaves da classe de entidades de origem.

Os mesmos identificadores que instanciavam a classe de entidades inicial, agora, instanciam cada um dos fragmentos.

A corretude da fragmentação depende da completude da operação, onde cada atributo deve ser mapeado em um atributo de cada fragmento, conforme as regras citadas na seção 3-2. A corretude da fragmentação depende também da possibilidade de reconstrução da classe de entidades original, que ocorre por meio de uma operação de agregação sobre os 


\section{Capítulo 5 - Fragmentação Primária do Diagrama ER}

fragmentos, considerando-se a associação implícita entre eles na forma de um relacionamento do tipo 1:1.

A disjunção entre os fragmentos não é requerida para este tipo de fragmentação, muito pelo contrário, a reconstrução da classe de entidades original depende da replicação de seus atributos chaves em cada um dos fragmentos. Em geral, duplicam-se apenas os atributos chaves.

A fragmentação é realizada considerando-se que os atributos a serem agrupados têm características desejáveis em comum. Por exemplo, consideremos a Figura 19, na qual estabeleceremos uma organização onde salários e fundos de garantia são tratados em separado dos demais atributos. Assim, uma fragmentação possível seria:

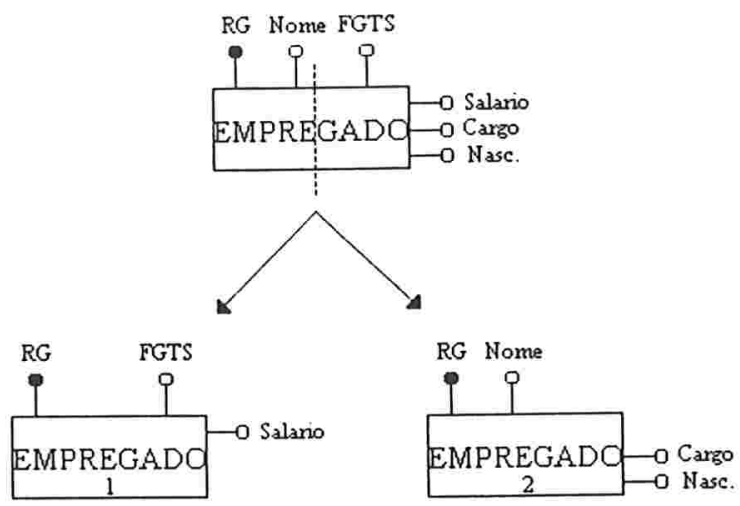

Figura 19: Fragmentação Vertical de Classes de Entidades

Para garantirmos que as três regras básicas de fragmentação, mencionadas anteriormente, sejam válidas para este tipo de fragmentação, analisaremos uma a uma.

A regra de completude é trivial neste tipo de fragmentação, pois cada um dos fragmentos recebe todos os identificadores que instanciam a classe de entidades original.

A reconstrução da classe de entidades original é alcançada através da agregação dos fragmentos através de uma relação implícita que consiste de um relacionamento do tipo 1:1 entre eles, conforme Figura 20.

A regra de disjunçào, como já mencionado anteriormente, não é requerida neste tipo de fragmentação. 
Capítulo 5 - Fragmentação Primária do Diagrama ER

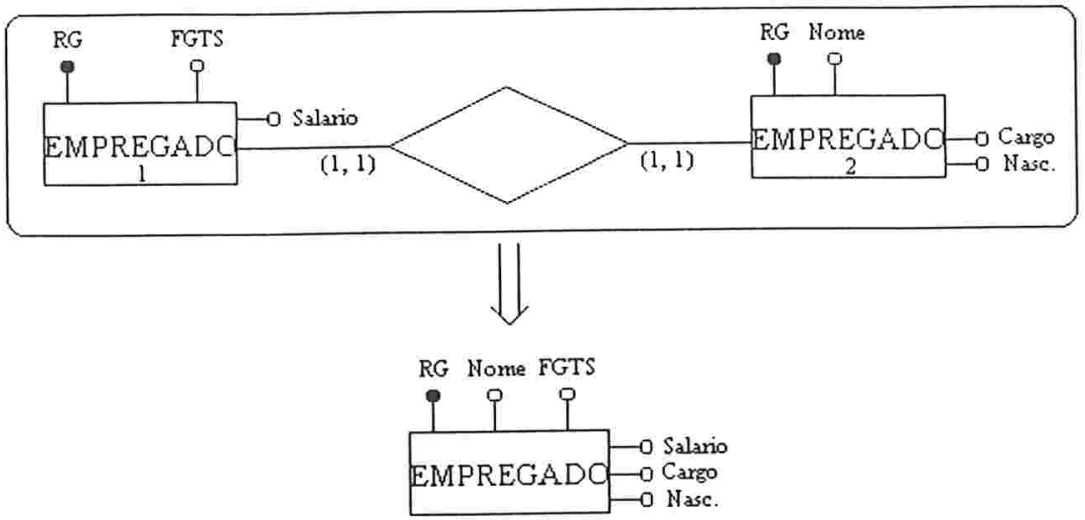

Figura 20: Operação de Agregação dos Fragmentos

\section{Fragmentação de Hierarquias de Generalização}

Conforme explicado anteriormente, no início deste capítulo, a fragmentação de hierarquias de generalização será abordada utilizando-se um diagrama ER composto apenas por hierarquias de generalizaçào.

A fragmentação de hierarquias de generalização utiliza os conceitos apresentados na seção 5-2, sobre a fragmentação de classes de entidades. Ela é formada por dois tipos básicos: a fragmentação horizontal e a fragmentação vertical. Ambos os tipos de fragmentação produzem novas hierarquias de generalização, e podem ser aplicados tanto à entidade "pai" quanto às entidades "filhas" de uma hierarquia de generalização.

Nas próximas seções, discutiremos os dois tipos básicos de fragmentação. Em cada um dos casos, trataremos da fragmentação da entidade "pai" e das entidades "filhas".

\subsection{Fragmentação Horizontal de Hierarquias de Generalização}

A fragmentação horizontal de hierarquias de generalização consiste na fragmentação horizontal das classes de entidades pertencentes a estas hierarquias.

Como visto anteriormente, as hierarquias de generalização são compostas por entidades "pai" e entidades "filhas", desta maneira, analisaremos separadamente cada um destes casos de fragmentação em uma hierarquia de generalização. 


\subsubsection{Fragmentação de Entidades "Pai"}

A fragmentação horizontal da entidade "pai" de uma hierarquia de generalização produz novas hierarquias (novas árvores), do mesmo tipo (total ou parcial). As novas entidades "pai" de cada uma das novas hierarquias produzidas incorporam as restrições impostas pela fragmentação. Tais restrições são então herdadas pelas entidades "filhas" de cada uma das hierarquias fragmentadas, ou seja, por todos os ramos de cada uma das novas árvores recursivamente.

Os mesmos identificadores que instanciavam a hierarquia original agora instanciam cada uma das hierarquias fragmentadas, obedecendo ao conjunto de restrições pertencentes a cada uma entidades que as compõem. Um exemplo deste tipo de fragmentação pode ser observado na Figura 21. Note-se que esta definição é válida para ambos os tipos de hierarquia, por isso representamos a hierarquia por um triângulo semi preenchido.

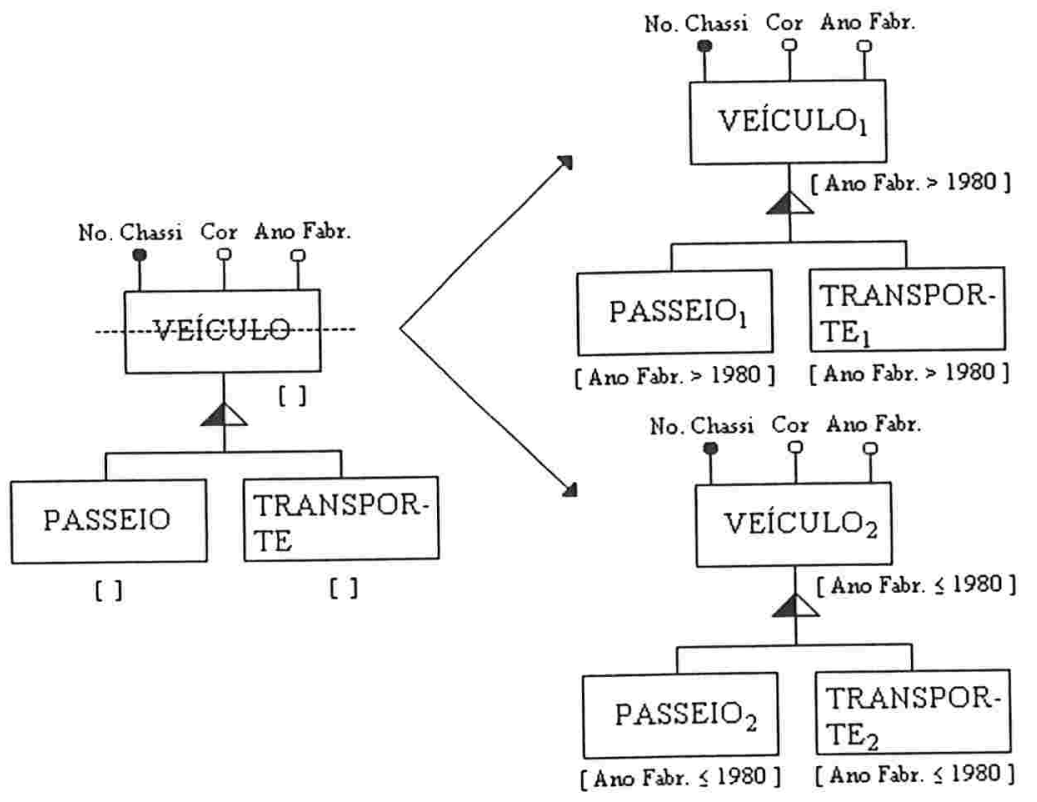

Figura 21: Fragmentação Horizontal de uma Entidade "Pai" em uma Hierarquia

A associação implícita existente entre os diagramas original e fragmentado é obtida da mesma maneira utilizada na seção 5-2.1, através de uma hierarquia de generalização total onde, neste caso, a entidade "pai" da hierarquia original ( I EICULO) torna-se "pai" da hierarquia implícita e seus "filhos" são representados pelas duas hierarquias fragmentadas. Tal associação pode ser melhor compreendida através da Figura 22. 


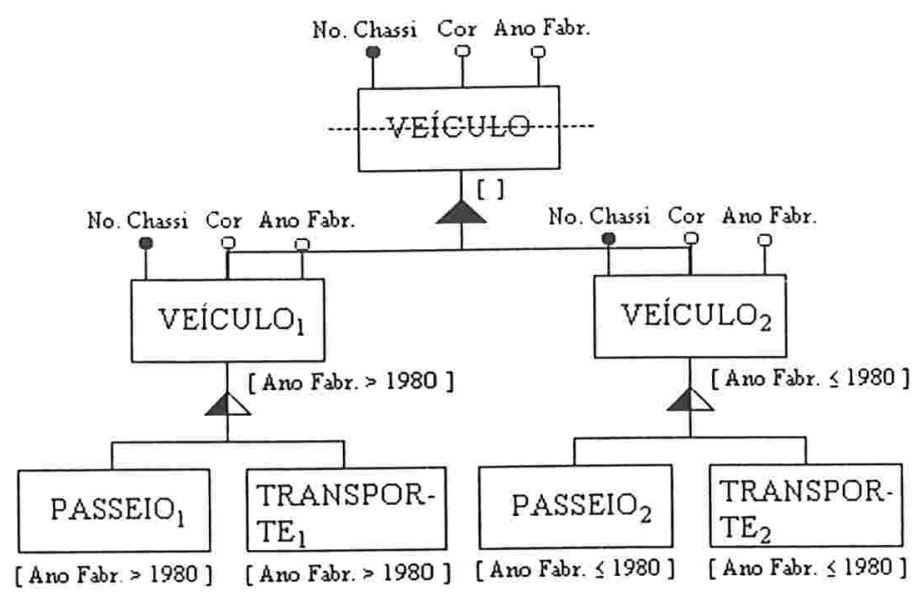

Figura 22: Associação Implícita entre Diagramas (Frag. Horizontal Hierarquias)

Para que a fragmentaçào seja correta, as regras básicas de fragmentação devem ser atendidas.

A completude da fragmentação é verificada, uma vez que todos os identificadores que instanciam cada uma das entidades "filhas" PASSEIO e TRANSPORTE estão representados nos fragmentos "filhos" PASSEIO, | PASSEIO, e TRANSPORTE, | TRANSPORTE $E_{2}$, respectivamente, dado que os conjuntos de restrições das hierarquias fragmentadas são complementares entre si.

A reconstrução da hierarquia original é garantida através de uma operação de união do conjunto de restrições de cada uma das novas hierarquias, a qual reproduzirá a hierarquia original.

A disjunção entre os fragmentos é trivialmente verificada, uma vez que as restrições [Ano Fabr: $\leq 1980]$ e [Ano Fabr. > 1980] são mutuamente excludentes.

\subsubsection{Fragmentação de Entidades "Filhas"}

A fragmentação horizontal de uma entidade "filha" de uma hierarquia de generalização não produz novas hierarquias (árvores), ela apenas acrescenta novas entidades/hierarquias "filhas" (novos ramos), resultantes da fragmentação, à hierarquia original. Um exemplo deste tipo de fragmentação pode ser observado na Figura 23. 


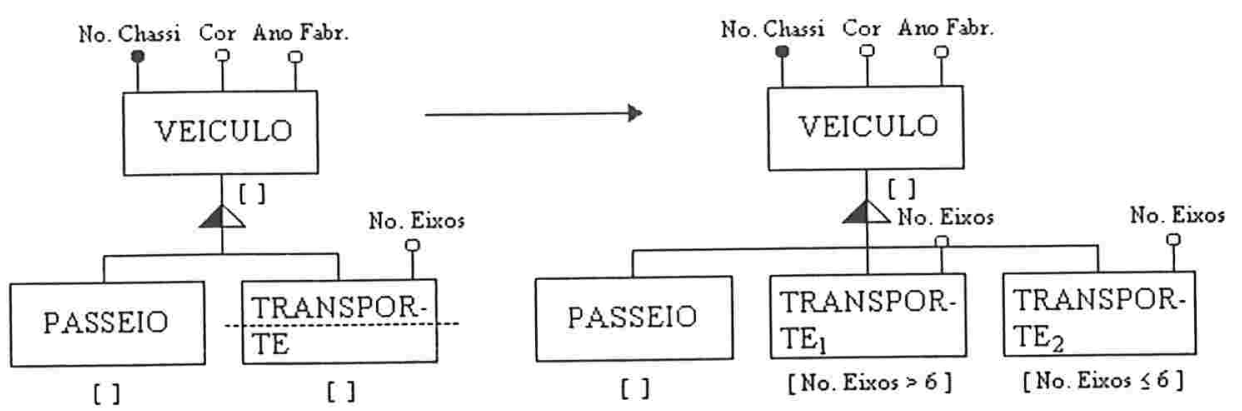

Figura 23: Fragmentação Horizontal de uma Entidade "Filha" em uma Hierarquia

O processo de fragmentação é o mesmo apresentado na seção 5-2.1 e as restrições incorporadas pelas novas classes de entidades "filhas" são, então, herdadas por todas as entidades pertencentes à sua sub-árvore, de acordo com o processo apresentado na seção 53.1.1.

A associação implícita existente entre os diagramas original e fragmentado também é a mesma apresentada na seção 5-2.1, ou seja, uma hierarquia de generalização total contendo a entidade "filha" original como entidade "pai", e os fragmentos como entidades "filhas" desta hierarquia, conforme a Figura 24.

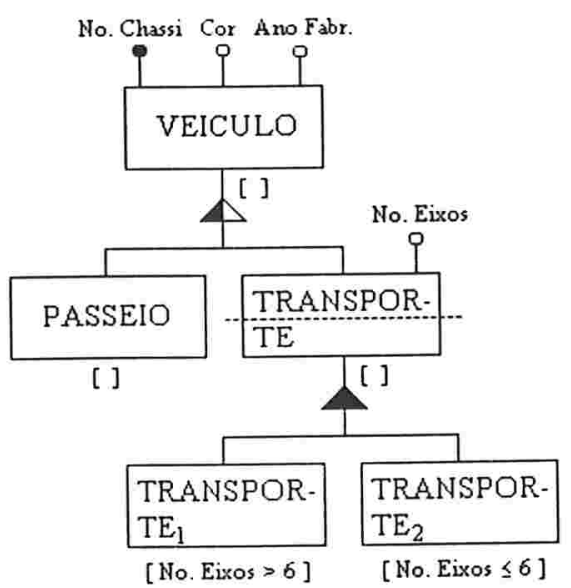

Figura 24: Associação Implícita entre Diagramas (Frag. Horizontal Hierarquias)

Os mesmos identificadores que instanciavam a entidade "filha" original agora instanciam cada uma das entidade "filhas" fragmentadas, obedecendo ao conjunto de restriçōes pertencentes a cada uma destas entidades.

Para verificarmos a corretude da fragmentação, analisaremos cada uma das regras básicas de fragmentação apresentadas na seção 3-2. 
Capítulo 5 - Fragmentação Primária do Diagrama ER

A completude da fragmentação é satisfeita, uma vez que todos os identificadores que instanciavam a entidade TRANSPORTE, passam a instanciar as entidades TRANSPORTE, e TRANSPORTE 2 . Isso pode ser facilmente comprovado, visto que a associação implícita existente entre os diagramas é composta de uma hierarquia total entre a entidade original e as novas entidades.

A reconstrução da entidade original (TRANSPORTE) é realizada através de uma operação de união dos conjuntos de restrições de cada um dos fragmentos, neste caso, $[$ No.Eixos $>$ G or $[$ No.Eixos $\leq 6]=1$.

A disjunção dos fragmentos é trivial, visto que as restrições [No.Eixos > 6] e $[$ No.Eixos $\leq$ G] são mutuamente excludentes.

\subsection{Fragmentação Vertical de Hierarquias de Generalização}

A fragmentação vertical de uma hierarquia de generalização consiste na fragmentação vertical das classes de entidades que a compõem. Novamente, as fragmentações de entidades "pai" e "filhas" em uma hierarquia de generalização serão apresentadas separadamente para melhor compreensão e visualização de cada caso.

\subsubsection{Fragmentação de Entidades "Pai"}

A fragmentação vertical de uma classe de entidades "pai" de uma hierarquia de generalização produz novas hierarquias (novas árvores), do mesmo tipo (total ou parcial) da hierarquia original.

As novas hierarquias possuem a mesma estrutura de classes de entidades da hierarquia original, porém seus esquemas são determinados pela fragmentação realizada sobre a entidade "pai" da hierarquia original, uma vez que as entidades "filhas" (ramos) herdam os atributos das entidades de maior nivel na hierarquia (seção 2-1.2.1) e mantêm seus atributos individuais.

Os mesmos identificadores que instanciavam a hierarquia original agora instanciam cada uma das hierarquias fragmentadas.

Um exemplo deste tipo de fragmentação pode ser encontrado na Figura 25. 


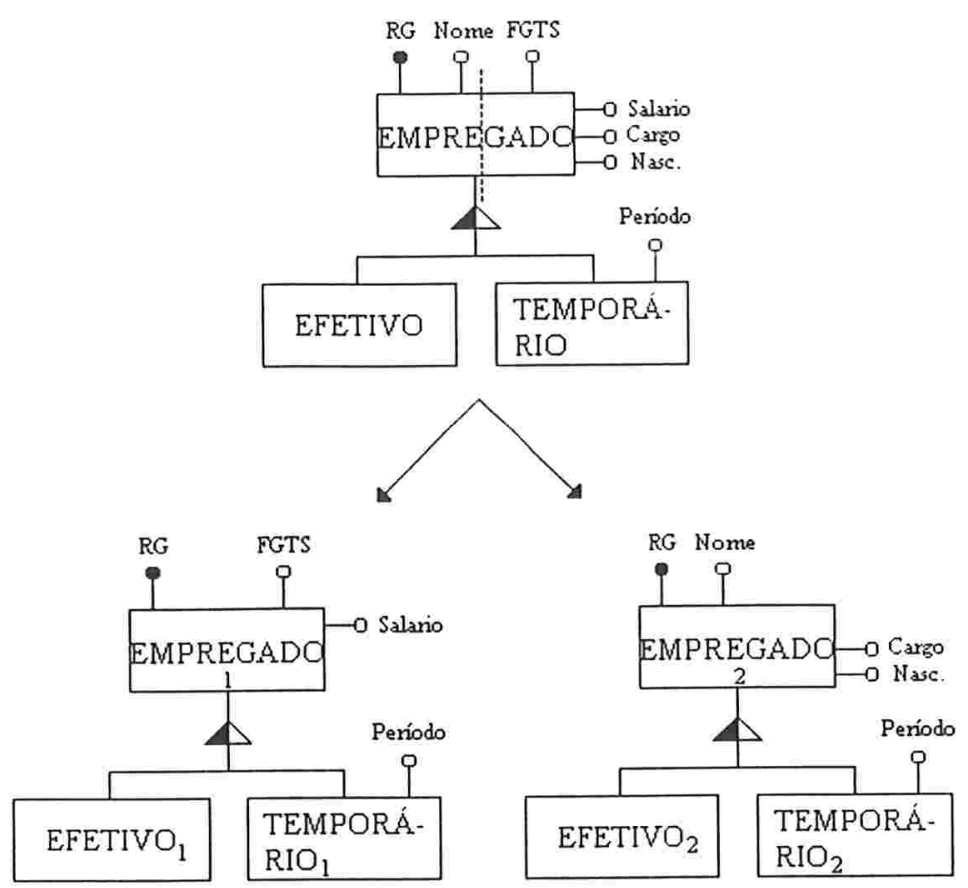

Figura 25: Fragmentação Vertical de uma Entidade "Pai" em uma Hierarquia

A associação implícita existente entre o diagrama original e o fragmentado para este tipo de fragmentação é representada por um relacionamento do tipo 1:1 entre as entidades "pai" das hierarquias fragmentadas, o qual é herdado, segundo a propriedade fundamental de abstração de generalização (seção 2-1.2.1), por todas as sub-árvores na hierarquia. A Figura 26 ilustra tal associação.

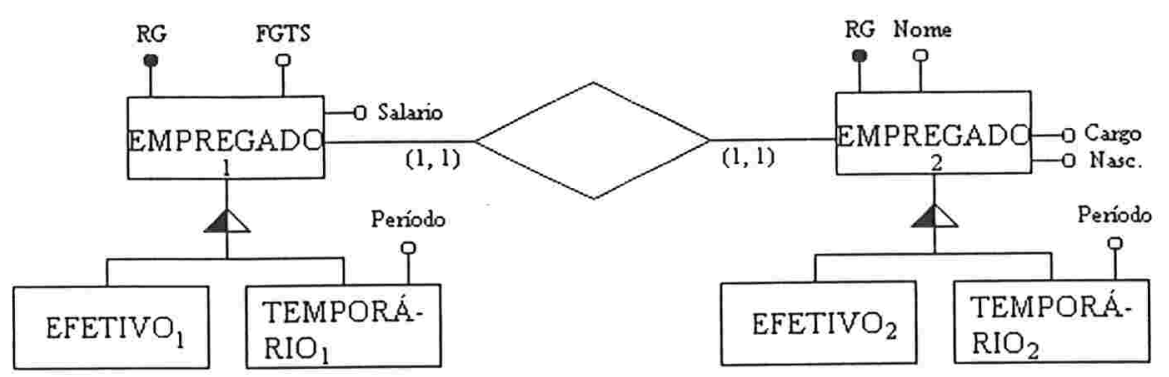

Figura 26: Associação Implícita entre Diagramas (Frag. Vertical Hieraquias)

Para comprovarmos a corretude da fragmentação devemos realizar a verificação das regras básicas de fragmentação.

A completude da fragmentação é satisfeita, uma vez que todos os identificadores que instanciavam a hierarquia original agora instanciam as novas hierarquias. A mudança 


\section{Capítulo 5 - Fragmentação Primária do Diagrama ER}

ocorrida em tal fragmentação refere-se apenas aos esquemas da entidades participantes nas novas hierarquias geradas, e não à instanciação de cada uma delas.

A reconstrução da hierarquia original é facilmente alcançada através da aplicação de uma operação de agregação entre as novas hierarquias (entidades "pai"), considerando-se a associação implícita (relacionamento 1:1) entre elas.

A regra de disjunção mais uma vez não se faz necessária para este tipo de fragmentação, conforme mencionado anteriormente.

\subsubsection{Fragmentação de Entidades "Filhas"}

A fragmentaçào vertical de uma entidade "filha" em uma hierarquia de generalização não produz novas hierarquias (árvores), ela apenas acrescenta novas entidades/hierarquias "filhas" (novos ramos) à hierarquia original, da mesma forma apresentada na seção 5-3.1.2.

$O$ processo de fragmentação segue as mesmas diretrizes de uma fragmentação vertical aplicada sobre uma classe de entidades qualquer, e os fragmentos resultantes substituem a entidade "filha" original na hierarquia de generalização.

Caso a entidade "filha" a ser fragmentada seja única em sua sub-árvore, ou seja, ela não possua "filhos", os únicos esquemas afetados na hierarquia são os esquemas das novas entidades geradas pela fragmentação. Caso contrário, ou seja, a entidade em questão seja também "pai" de uma sub-hierarquia, a fragmentação acrescentará novas hierarquias ao invés de simples entidades à hierarquia original, e neste caso a estrutura dos esquemas de cada uma das novas sub-hierarquias segue as diretrizes definidas na seção 5-3.2.1, que trata da fragmentação de entidades "pai" em uma hierarquia.

Este tipo de fragmentação foi apresentado simplesmente com o intuito de completar a teoria sobre fragmentação de hierarquias de generalização, já que a fragmentação vertical de uma entidade "filha" em uma hierarquia de generalização nada mais é que um refinamento da hierarquia.

Não conhecemos aplicações para tal tipo de operação na fragmentação do ME-R visando a distribuição dos dados, por este motivo não são apresentados exemplos para este tipo de fragmentação. 


\section{Fragmentação Derivada Estrutural do Diagrama ER}

Na fragmentação, seja ela horizontal ou vertical, de uma classe de entidades (ou hierarquia de generalização), novas classes de entidades (ou hierarquias) são produzidas. Tais novas classes podem ou não diferirem da classe de origem quanto ao seu esquema ou quanto à incorporação de restrições provenientes da linguagem de consulta utilizada.

Porém, a teoria apresentada no capítulo 5 utiliza-se de diagramas ER que contêm única e exclusivamente os elementos a serem estudados, como classes de entidades e hierarquias de generalização, sem mencionar nenhum tipo de relacionamento envolvendo tais elementos.

Quando analisamos a fragmentação de elementos que não se encontram "isolados" no diagrama, temos que considerar os efeitos produzidos por uma operação de fragmentação sobre todos os demais elementos deste diagrama que direta, ou indiretamente, relacionam-se com o elemento fragmentado. Uma vez que a fragmentação de um elemento no diagrama resulta na fragmentação de outro(s) elemento(s) deste diagrama, dizemos que tais fragmentações são derivadas da fragmentação inicial.

Este capítulo destina-se ao estudo dos casos de fragmentação derivada sobre uma composição dos elementos do modelo entidade-relacionamento e, principalmente, à introdução do fato da fragmentação derivada no modelo entidade-relacionamento ser totalmente proveniente da estrutura do diagrama ER e não da aplicação de consultas, como no caso do modelo relacional de dados.

\section{Fragmentação Derivada Primária}

Nesta seção, analisaremos os efeitos da fragmentação de um dos elementos do diagrama sobre os relacionamentos dos quais o elemento fragmentado participa.

Como mencionado anteriormente, uma fragmentação de elementos como uma classe de entidades ou uma hierarquia de generalização, seja ela horizontal ou vertical, produz 


\section{Capítulo 6 - Fragmentação Derivada Estrutural do Diagrama ER}

novas entidades (ou hierarquias). Estes novos elementos resultantes da fragmentação herdam todos os relacionamentos dos quais o elemento original era participante. Por exemplo, se uma classe de entidades Ent, que participa dos relacionamentos $\operatorname{Rel}_{1}$ e $\mathrm{Rel}_{2}$, é fragmentada (horizontal ou verticalmente) produzindo os fragmentos $E n t_{1}$, Ent $t_{2}$ e Ent $t_{3}$, tais fragmentos herdam, cada um deles, os relacionamentos nos quais a entidade Ent participava, neste caso $\mathrm{Rel}_{1}$ e Rel, com seus respectivos atributos e restrições de cardinalidade.

A Figura 27 ilustra um exemplo onde ocorre a fragmentação horizontal de uma classe de entidades participante de um relacionamento no diagrama original. Tal fragmentação produz um novo diagrama (distribuído) composto por duas novas classes de entidades (EMPREGADO, e EMPREGADO $)_{2}$, com seus respectivos conjuntos de restrições e relacionamentos, além da classe de entidades DEPARTAMENTO que agora participa de mais um relacionamento, sem perda de generalidade.
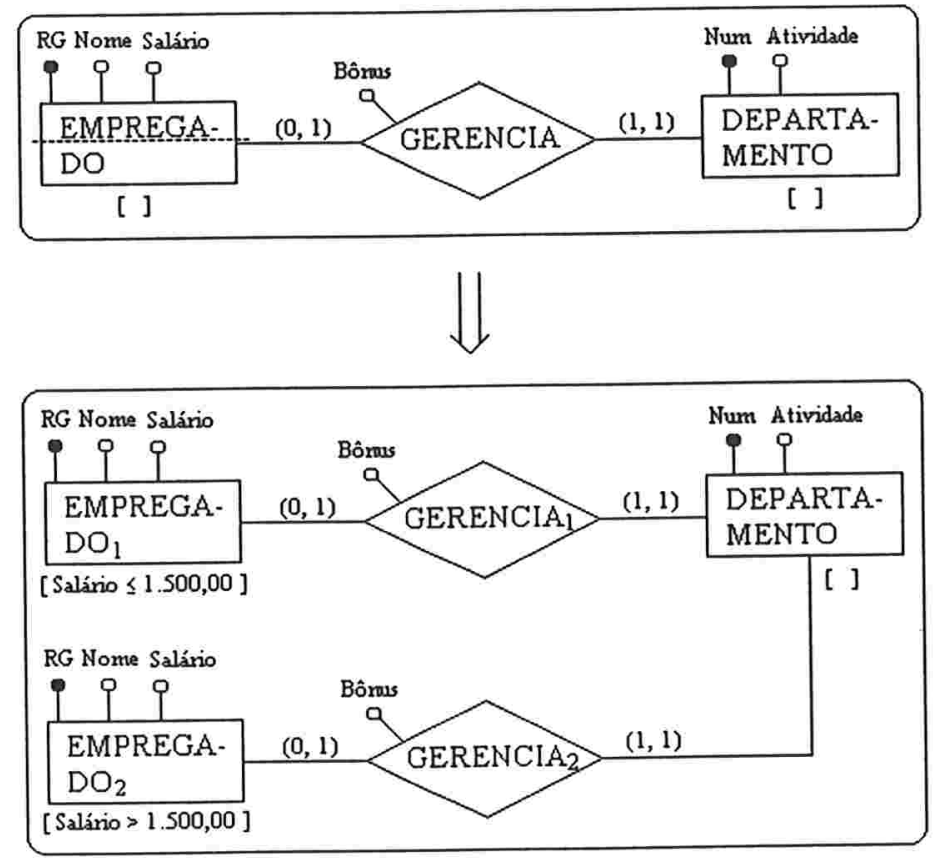

Figura 27: Fragmentação Horizontal Derivada Primária

Analogamente, caso a fragmentação aplicada sobre a entidade EMPREGADO fosse vertical, ao invés de horizontal, o efeito produzido seria o mesmo para este caso primário de fragmentação derivada, que pode ser visto na Figura 28. 


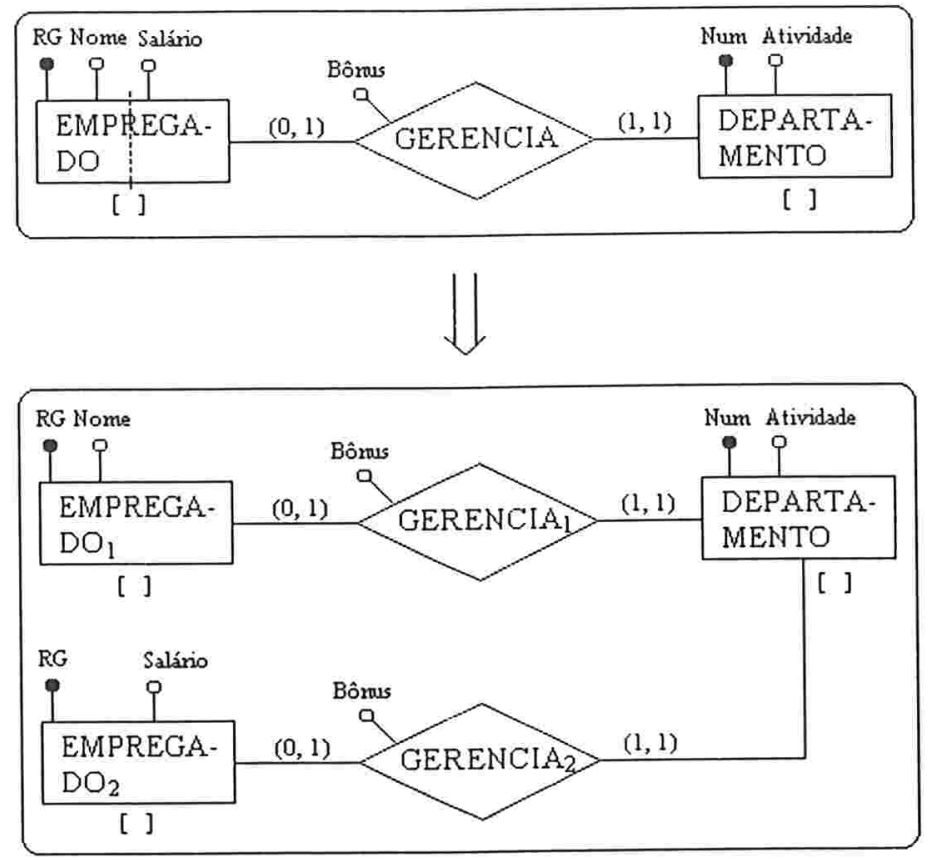

Figura 28: Fragmentação Vertical Derivada Primária

Para os dois casos de fragmentação, existe uma análise a ser realizada sobre as cardinalidades que caracterizam o relacionamento fragmentado.

Caso a cardinalidade-máxima entre o relacionamento e $a(s)$ entidade(s) não fragmentada(s) for igual a $N$, o relacionamento não garante a disjunção entre os fragmentos, ou seja, uma mesma instância pertencente a uma entidade não fragmentada pode se relacionar com instâncias pertencentes a diferentes fragmentos.

Caso a cardinalidade-máxima entre o relacionamento e a(s) entidade(s) nãofragmentada(s) for igual a 1, o relacionamento garante a disjunção entre os fragmentos, ou seja, uma mesma instância pertencente a uma entidade não-fragmentada deverá se relacionar com, no máximo, uma instância pertencente a algum dos fragmentos.

Nos exemplos acima, as cardinalidades $(1,1)$ que caracterizam a participação da entidade não-fragmentada DEPARTAMENTO no relacionamento GERENCLA garantem a disjunção entre os fragmentos, ou seja, uma mesma instância da entidade DEPARTAMENTO deve se relacionar com apenas uma instância de um dos fragmentos.

Ainda nos exemplos acima, dependendo do contexto da aplicação de banco de dados, a fragmentação realizada sobre a entidade EMPREGADO poderia resultar na 


\section{Capítulo 6 - Fragmentação Derivada Estrutural do Diagrama ER}

necessidade de fragmentação da entidade DEPARTAMENTO. Tal fragmentação derivada representa a propagação dos efeitos gerados pela operação de fragmentação inicial, através do grafo que representa o diagrama recursivamente.

O estudo dos casos de propagação (derivação) recursiva da fragmentação é discutido na seção 6-3. A próxima seção apresenta a fragmentação de elementos auto-relacionados.

\section{Fragmentação de Elementos Auto-Relacionados}

A fragmentação de elementos auto-relacionados, sejam eles classes de entidades ou hierarquias de generalização, segue os mesmos princípios apresentados nas demais seções que compõem este capítulo.

Ilustraremos a fragmentação de uma classe de entidades que possui um autorelacionamento por meio de um exemplo para melhor compreensão do processo.

Consideremos o exemplo da Figura 29, onde fragmentaremos a entidade EMPREGADO, horizontalmente, pelo atributo Salário, produzindo dois fragmentos. Vale notar que a fragmentação aplicada sobre a entidade EMPREGADO produziria o mesmo efeito se fosse realizada verticalmente.

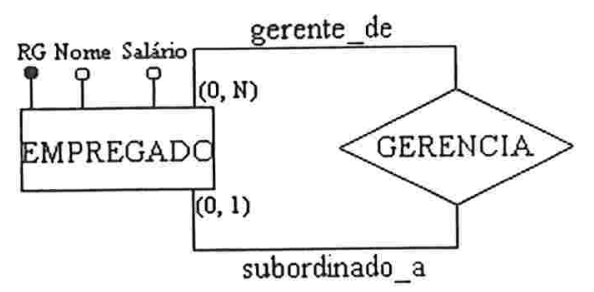

Figura 29: Fragmentação de um Auto-Relacionamento

Sem perda de generalidade, transformaremos o auto-relacionamento GERENCLA em um relacionamento binário criando duas cópias da entidade EMPREGADO, EMPREGADO, e EMPREGADO 2 , produzindo o diagrama da Figura 30.

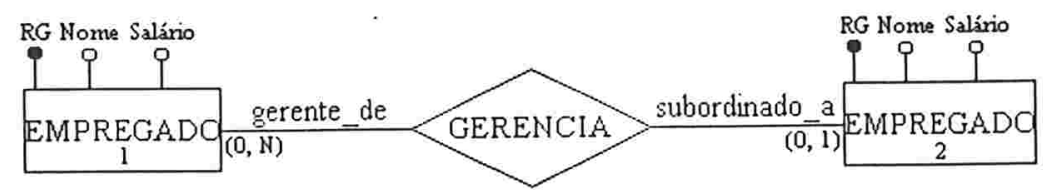

Figura 30: Relacionamento Binário 
Capítulo 6 - Fragmentação Derivada Estrutural do Diagrama ER

Aplicando a fragmentação sobre a entidade EMPREGADO, produzimos os fragmentos EMPREGADO,.. e EMPREGADO,.2, com seus respectivos conjuntos de restrições. A Figura 31 ilustra a operação.

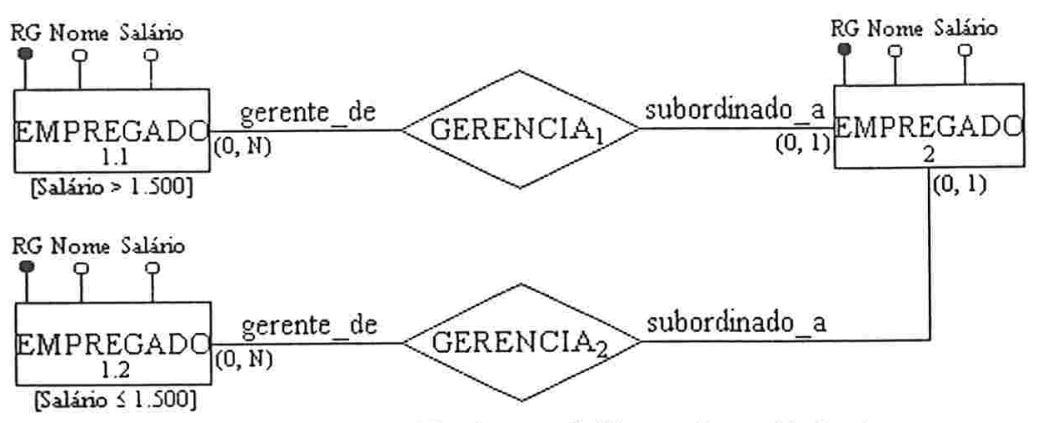

Figura 31: Fragmentação Horizontal (1) em Auto-Relacionamento

Repetindo a operação em EMPREGADO, produzimos os fragmentos EMPREGADO $O_{2.1}$ e EMPREGADO ${ }_{2.2}$ que, conforme a primeira operação, herdam os seus relacionamentos, resultando no diagrama da Figura 32.

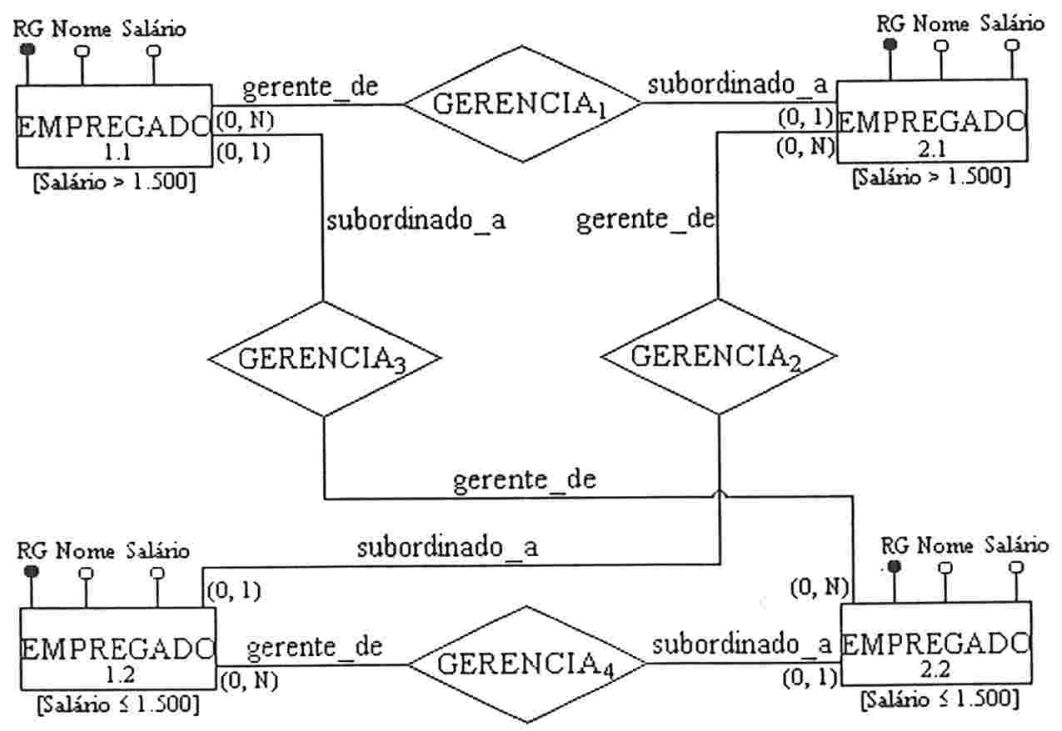

Figura 32: Fragmentação Horizontal (2) em Auto-Relacionamento

Como EMPREGADO, e EMPREGADO, são cópias de EMPREGADO o diagrama final pode ser visto na Figura 33. 


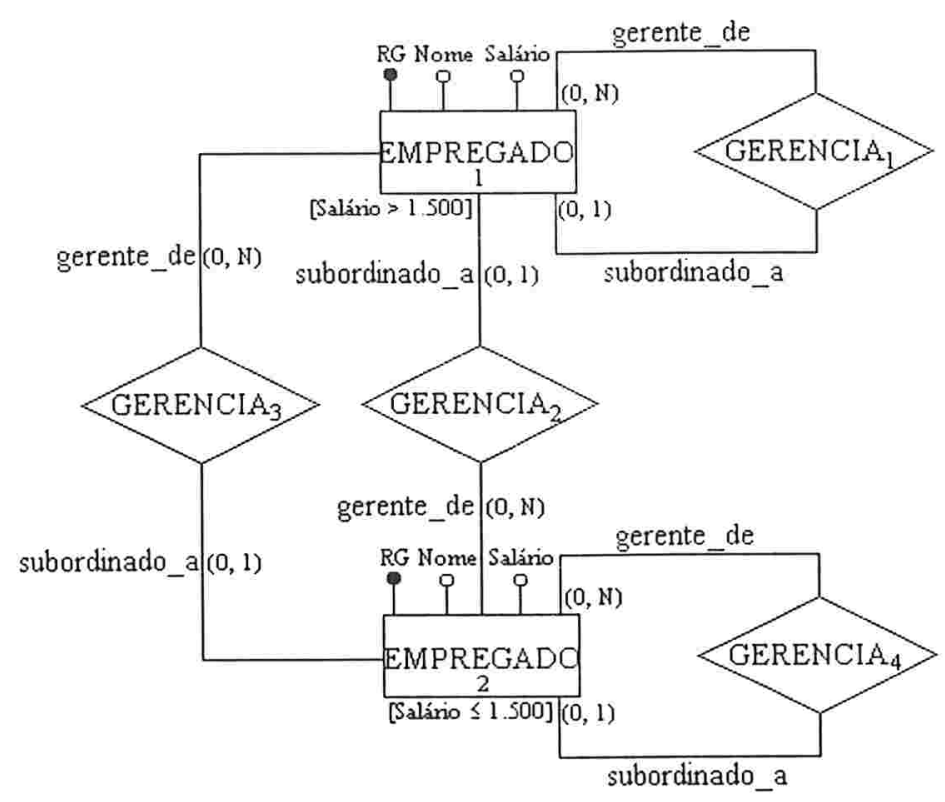

Figura 33: Diagrama ER Final (Auto-Relacionamento)

É importante notarmos que alguns relacionamentos resultantes da fragmentação podem ser vazios e não necessitam ser mostrados no diagrama. Por exemplo, se soubermos de antemão que todos os gerentes possuem um salário maior que 1.500, os relacionamentos GERENCLA, e GERENCLA $A_{2}$ seriam vazios e poderiam ser ocultados no diagrama.

\section{Fragmentação Derivada Recursiva}

$\mathrm{Na}$ seção anterior, foram apresentados os efeitos da fragmentação sobre os relacionamentos nos quais o elemento fragmentado é participante, onde pudemos constatar a analogia entre os casos de fragmentação horizontal e vertical.

Nesta seção investigaremos os casos de propagação da fragmentação, não somente sobre os relacionamentos diretos, mas também sobre entidades relacionadas, direta ou indiretamente, ao elemento fragmentado, seja ele uma classe de entidades ou uma hierarquia de generalização.

Quando analisamos a propagação de uma fragmentação, através do grafo que representa um diagrama ER, devemos considerar o contexto da aplicação de banco de dados, a fim de estabelecermos limites de alcance para a propagação de uma fragmentação. Tais limites de alcance se referem à definição do caminho, no grafo que representa o diagrama ER, que será afetado pela fragmentação. 


\section{Capítulo 6 - Fragmentação Derivada Estrutural do Diagrama ER}

A definição destes caminhos é única para cada tipo de aplicação de banco de dados e crucial para o sucesso de um projeto de distribuição de um banco de dados.

A fragmentação derivada em um diagrama ER é definida sobre os conjuntos de restrições dos elementos fragmentados. Por este motivo ela é também denominada fragmentação horizontal derivada. Por conseqüência disto, podemos afirmar que a propagação de uma fragmentação pelo diagrama ER somente faz sentido quando esta fragmentação é horizontal. Como visto na seção 6-1, a fragmentação vertical de um elemento do diagrama somente afeta os relacionamentos nos quais ele participa diretamente.

Para ilustrarmos a teoria apresentada acima, reconsideremos o exemplo da Figura 27, supondo agora a fragmentação horizontal da entidade DEPARTAMENTO. Tal fragmentação poderia, dependendo do contexto da aplicação, exigir a fragmentação da entidade EMPREGADO. Caso esta fragmentação fosse necessária, ela seria uma fragmentação também horizontal e derivada da fragmentação horizontal da entidade DEPARTAMENTO.

$\mathrm{Na}$ teoria sobre fragmentação no diagrama ER, apresentada no capítulo 5, a fragmentação horizontal de uma classe de entidades era realizada através da incorporação de um conjunto de restrições baseadas nos atributos da própria entidade a ser fragmentada.

Desta maneira, ao fragmentarmos a entidade DEPARTAMENTO a partir de um conjunto de restrições baseado no atributo Atividade, deduzimos que a fragmentação da entidade EMPREGADO também deva ser realizada em relação à divisão departamental. Porém, a entidade EMPREGADO não possui nenhum atributo referente ao departamento a que suas instàncias pertencem. Assim, a fragmentação da entidade EMPREGADO deve ser realizada através da incorporação de um conjunto de restrições baseado nos atributos da entidade DEPARTAMENTO, e não baseado nos seus próprios atributos. Estas restrições serão realizadas na forma de uma fórmula de caminho, conforme visto na seção 4-3.

O conjunto de restrições que caracterizará as novas classes de entidades é composto pela conjunção booleana (AND) entre as restrições anteriores pertencentes à classe de entidades original com as restrições referentes à fragmentação derivada. No exemplo acima, a entidade original EMPREGADO possuía um conjunto vazio de restrições, portanto as novas entidades serào caracterizadas somente pelas restriçōes referentes à fragmentaçào 
Capítulo 6 - Fragmentação Derivada Estrutural do Diagrama ER

derivada. No caso, o caminho inicial que unia DEPARTAMENTO a EMPREGADO será desdobrado em dois, um para cada fragmento de DEPARTAMENTO:

\section{EMPREGADO, Gerencia DEPARTAMENTO . \{Atividade $=$ "RH" $\}$ \\ EMPREGADO, Gerencia DEPARTAMENTO $2 .\{$ Atividade = "Projetos" $\}$,}

onde a parte sublinhada é a restrição à entidade fragmentada.

Conforme mencionado anteriormente, as restrições resultantes da fragmentação derivada são obtidas através da aplicação de consultas no diagrama. Após a aplicação de tais consultas para a formação dos conjuntos de restrições, o diagrama resultante apresenta-se na Figura 34, que ilustra todo o processo de fragmentação, desde a fragmentação inicial aplicada sobre a entidade DEPARTAMENTO até a propagação da mesma sobre a entidade EMPREGADO.
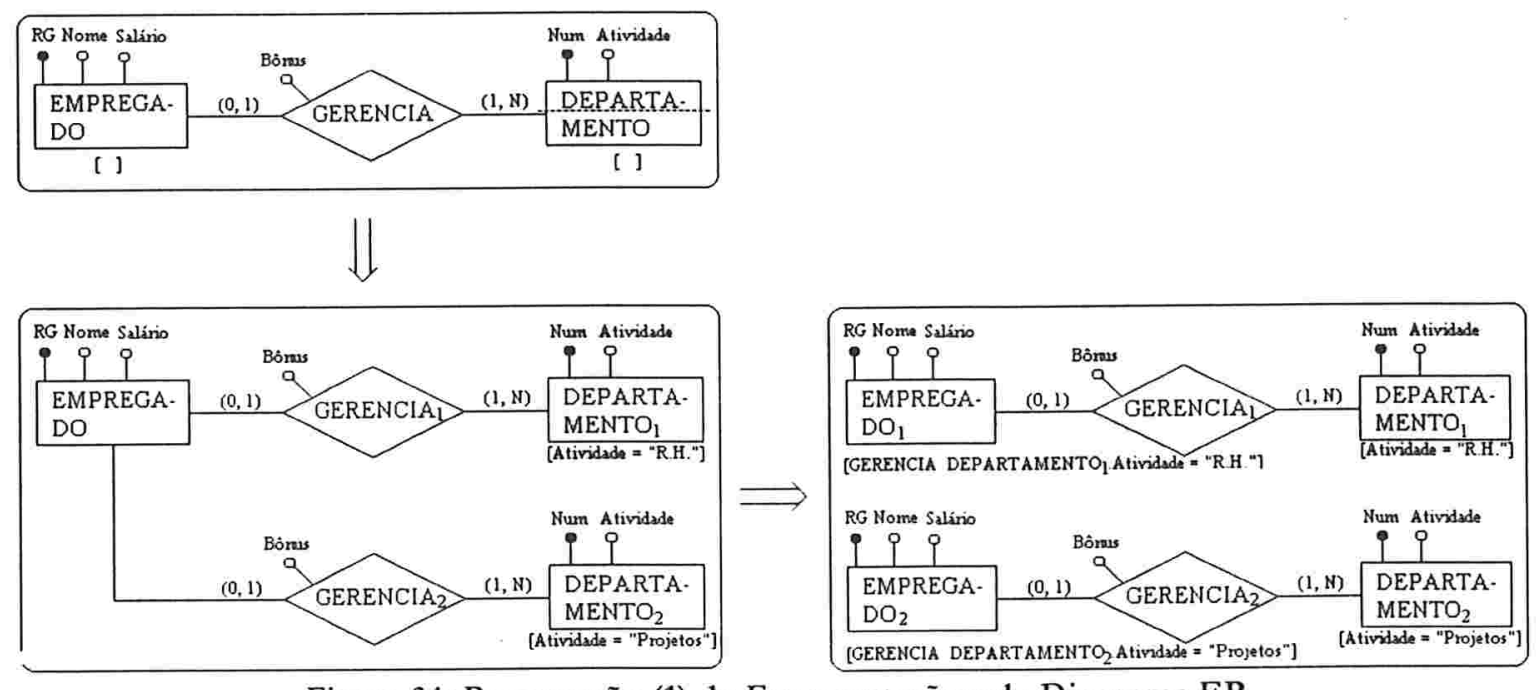

Figura 34: Propagação (1) da Fragmentação pelo Diagrama ER

No exemplo acima, caso a entidade DEPARTAMENTO participasse de outros relacionamentos, estes seriam herdados pelos fragmentos DEPARTAMENTO, e DEPARTAMENTO, como visto anteriormente na seção 6-1. Neste caso, a fragmentação realizada no exemplo poderia propagar-se ainda, recursivamente, pelas demais entidades do diagrama, seguindo a mesma filosofia apresentada nesta seção. 
Conforme visto na seção 5-2, as cardinalidades determinam a disjunção entre os fragmentos. No caso da fragmentação derivada recursiva, as cardinalidades, além de determinarem a disjunção, determinam o número de novos relacionamentos que serão criados na fragmentaçào.

No caso da cardinalidade-máxima, que caracteriza a participação do elemento a sofrer a fragmentação derivada recursiva no relacionamento, ser igual a 1 , a fragmentação ocorre conforme apresentado na Figura 34; apenas dois novos relacionamentos são criados, um para cada fragmento.

No caso desta cardinalidade-máxima ser igual a $N$, em vez de duas entidades e dois relacionamentos, teremos três entidades e quatro novos relacionamentos. A criação de uma terceira entidade se faz necessária para haver a disjunção entre os fragmentos.

Alterando o esquema de fragmentação do diagrama ilustrado na Figura 34, a partir da fragmentação primária de EMPREGADO e da fragmentação derivada de DEPARTAMENTO, as cardinalidades de participação da entidade DEPARTAMENTO no relacionamento GERENCLA determinam o número de novos relacionamentos a serem criados, conforme mostra a Figura 35.
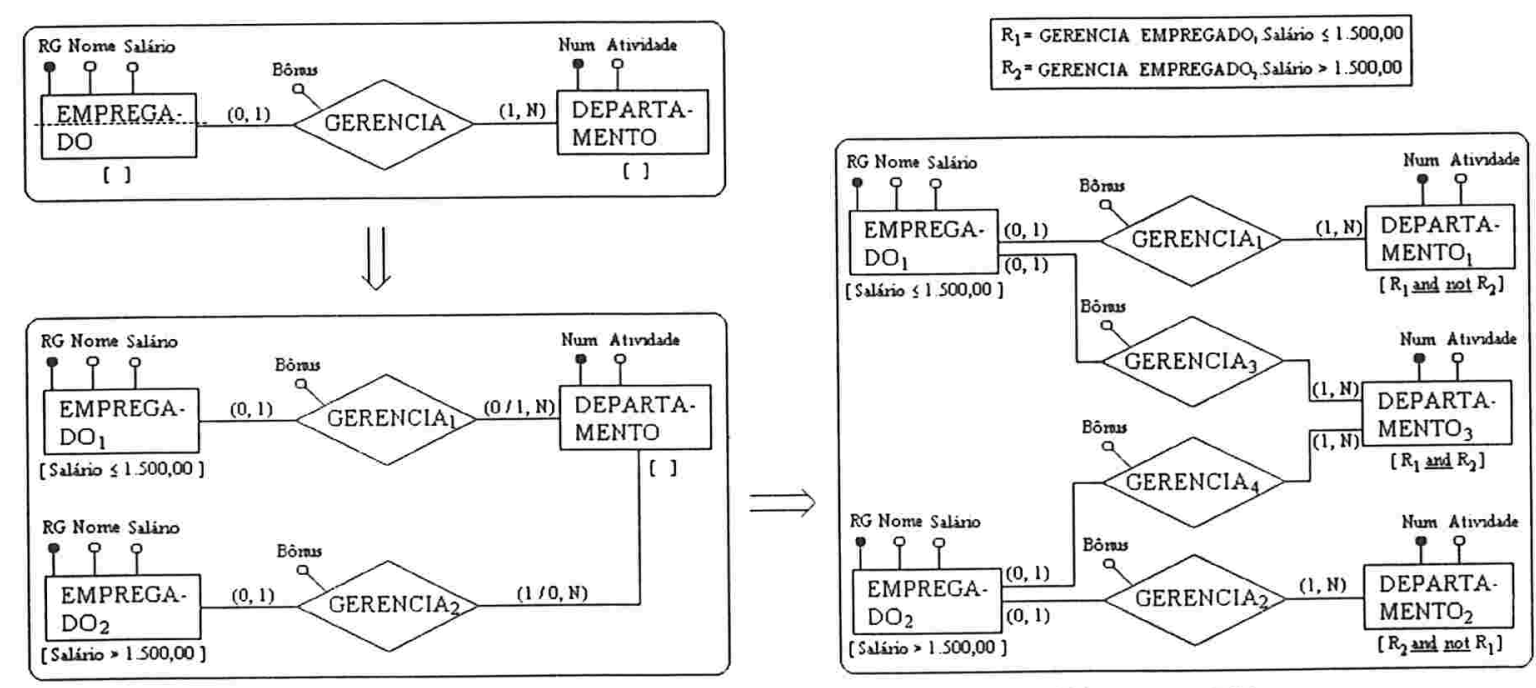

Figura 35: Propagação (2) da Fragmentação pelo Diagrama ER

No diagrama inicial, temos que os departamentos podem ser co-gerenciados por vários empregados devido à cardinalidade máxima $N$, e os salários dos gerentes podem ser, a princípio, qualquer. Portanto, a fragmentação derivada deve nos fornecer departamentos gerenciados apenas por empregados de salário inferior a 1.500,00, departamentos gerenciados apenas por empregados de salário superior a 1.500,00, e departamentos em que 
há pelo menos um gerente com salário acima e um gerente com salário abaixo de 1.500,00. Desta forma teremos très entidades e a existência de quatro relacionamentos decorre deste fato.

Por outro lado, se a cardinalidade-máxima fosse igual a 1 , os relacionamentos GERENCLA, e GERENCLA $A_{+}$seriam vazios e poderiam ser ocultados no diagrama, além da não existência da nova entidade $\left(D E P A R T A M E N T O_{3}\right)$, conforme a Figura 34.

Suponhamos que Gerenciado_por é um "alias" de Gerencia (prática comum no ME-R, e.g. [2] e [9]) e:

$$
\begin{aligned}
& \mathrm{R}_{1}=\text { DEPARTAMENTO Gerenciado_por EMPREGADO, } \\
& \mathrm{R}_{2}=\text { DEPARTAMENTO Gerenciado_por EMPREGADO, }
\end{aligned}
$$

então, o fragmento que contém apenas co-gerentes com salários inferiores (superiores) a $1.500,00$ é caracterizado pela restrição $R_{1}$ and not $R_{2}\left(R_{2}\right.$ and not $\left.R_{1}\right)$ e o fragmento com ambos os tipos de gerentes é caracterizado por $R_{1}$ and $R_{2}$. Assim, temos garantida tanto a disjunção desta fragmentação derivada, pela mútua exclusão lógica, como a completude, pois uma das restrições sempre é verdadeira. A reconstrutibilidade é garantida por construção.

Em geral, uma fragmentação primária de uma entidade em $N$ gera outras, por fragmentação derivada através de relacionamento de cardinalidade máxima ilimitada, $2^{x}-1$ novas entidades e $N \cdot 2^{(N-1)}$ novos relacionamentos.

\section{Exemplo Final}

Nesta seção, apresentaremos um exemplo completo de fragmentação derivada, a fim de melhor visualizarmos os efeitos produzidos por uma operação de fragmentação no diagrama ER.

Ao contrário dos demais exemplos apresentados nesta dissertação, este exemplo possui várias entidades, atributos, seus respectivos relacionamentos e cardinalidades, e representa um contexto real de modelagem. Isto é essencial para que as operações de fragmentação realizadas sobre o diagrama possam ser devidamente interpretadas e analisadas quanto à sua viabilidade e eficiência. 
Capítulo 6 - Fragmentação Derivada Estrutural do Diagrama ER

O diagrama da Figura 36 representa o esquema do banco de dados de uma empresa que se encontra centralizado e que se pretende distribuir. O critério considerado pela empresa para o processo de distribuição deste banco de dados é a atribuição de autonomia a cada um dos seus departamentos, o departamento de recursos humanos, de finanças e de informática.

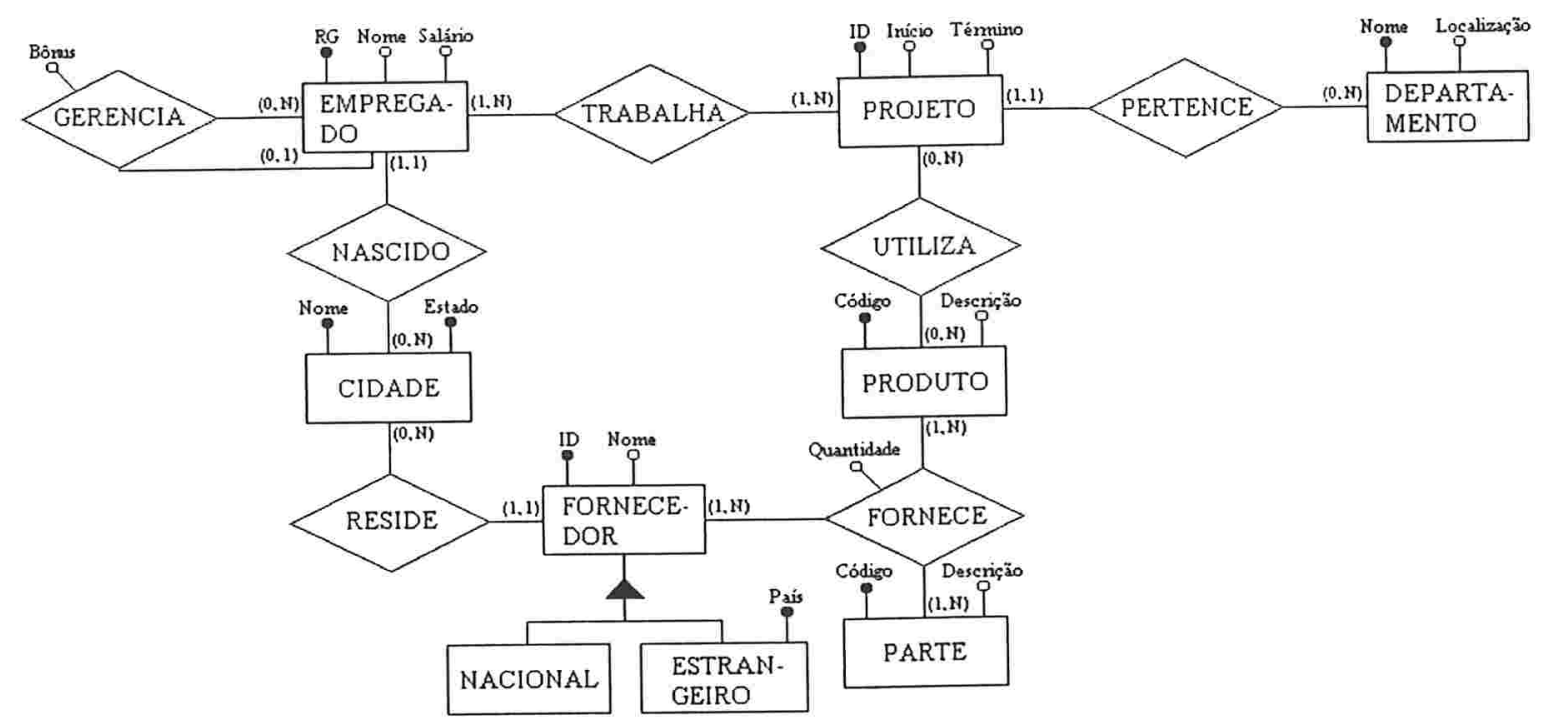

Figura 36: Diagrama ER Global

Para tal, a primeira operação a ser realizada sobre o diagrama acima é a fragmentação horizontal da entidade DEPARTAMENTO de acordo com o atributo Nome. Esta fragmentação produz três novas entidades DEPARTAMENTO, DEPARTAMENTO 2 DEPARTAMENTO , com seus respectivos conjuntos embutidos de restrições, [Nome = 'R.H.'], [Nome = 'Finanças'] e [Nome = "Informática']. Esta primeira operação pode ser visualizada na Figura 37. 


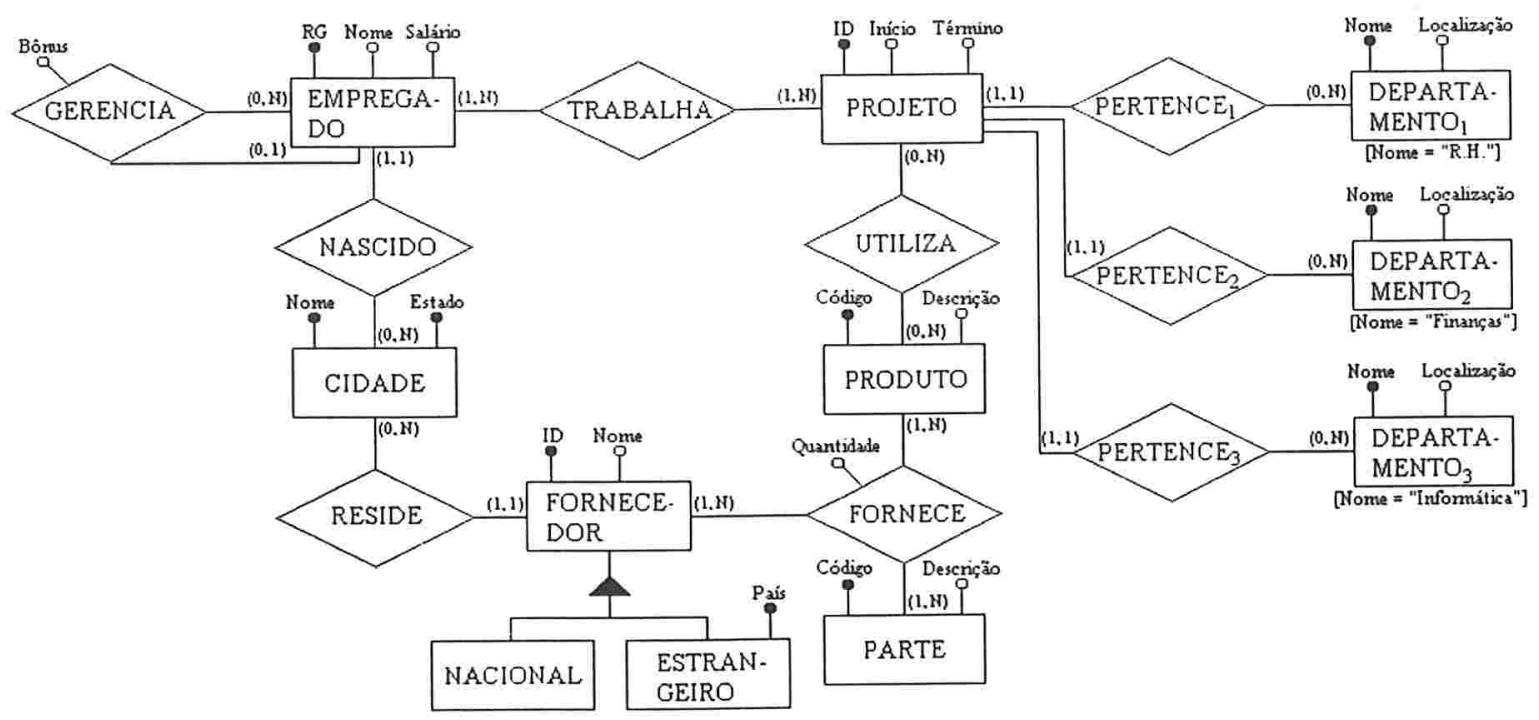

Figura 37: Fragmentação Horizontal Inicial

Nesta figura, podemos notar que a fragmentação da entida de DEPARTAMENTO produz a fragmentação do relacionamento PERTENCE, para que a propriedade de herança dos relacionamentos seja seguida, conforme apresentado na seção 6-1.

Uma importante consideração a ser feita sobre a fragmentação derivada primária do relacionamento PERTENCE é que deve estar claro, com referência à seção 6-1, que existe a disjunção entre os fragmentos da entidade DEPARTAMENTO, ou seja, uma instância da entidade PROJETO pode se relacionar com somente uma instância da entidade DEPARTAMENTO em apenas um dos fragmentos. Isto é garantido pelas cardinalidades (1, 1) com que a entidade PROJETO participa do relacionamento PERTENCE.

Após a fragmentação inicial do diagrama, devemos analisar a necessidade, ou não, da propagação desta fragmentação através dos demais elementos do diagrama.

De acordo com o grafo que representa o diagrama, o único elemento que devemos considerar em primeira instância é a entidade PROJETO. Como a proposta da empresa para a fragmentação do seu banco de dados era fornecer autonomia aos departamentos, devemos supor que cada departamento deva deter o controle sobre seus projetos.

Desta maneira, a entidade PROJETO deve ser fragmentada de acordo com o departamento ao qual pertencem cada uma das suas instâncias. A Figura 38 ilustra a fragmentação horizontal derivada da entidade PROJETO, que produz très novas entidades, PROJETO, PROJETO $_{2}$ e PROJETO ${ }_{3}$, com seus respectivos conjuntos de restrições. Deve-se notar que os conjuntos de restrições de cada uma das novas entidades está representado por 


\section{Capítulo 6 - Fragmentação Derivada Estrutural do Diagrama ER}

uma legenda que se encontra no canto inferior direito da figura. Tal representação visa à não "sobrecarga" da figura e pode ser realizada sempre que necessário.

Podemos observar na Figura 38 que, assim como na fragmentação anterior, esta também culmina na fragmentação de relacionamentos, neste caso de dois deles, os relacionamentos TRABALHA e UTILIZA, que são herdados pelos novos fragmentos. Além disso, vale ressaltar que as entidades EMPREGADO e PRODUTO aumentaram suas participações em relacionamentos, relacionando-se também com cada um dos novos fragmentos.

A fragmentação do relacionamento TRABALHA não requer a disjunção entre os fragmentos da entidade PROJETO, uma vez que as cardinalidades $(1, N)$ com que a entidade EMPREGADO participa deste relacionamento não garantem tal disjunção (vide seção 6-1). A mesma coisa acontece com o relacionamento UTILIZA, que também não exige a disjunção entre os fragmentos da entidade PROJETO, ou seja, uma mesma instância da entidade PRODUTO pode se relacionar com várias instâncias pertencentes a diferentes fragmentos da entidade DEPARTAMENTO.

De maneira recursiva e independente do contexto, poderíamos aplicar a propagação da fragmentação inicial da entidade DEPARTAMENTO sobre todo o grafo, porém, o contexto da aplicação deve ser considerado na geração do esquema distribuído de um banco de dados. Portanto, seguiremos questionando a necessidade de propagação, definindo, assim, o caminho no grafo "afetado" pela fragmentação inicial, ou o escopo da propagação.

Analisando o grafo da Figura 38, existem dois caminhos que devem ser considerados para a propagação da fragmentação da entidade PROJETO, que se iniciam nas entidades EMPREGADO e PRODUTO.

Suponhamos que a empresa não deseja conceder o controle sobre os empregados a cada departamento, ou seja, o controle é realizado de forma centralizada. Assim, a entidade EMPREGADO não faz parte do escopo de propagação da fragmentação.

De forma análoga, o controle sobre os produtos utilizados pelos projetos deve ser realizado igualmente de maneira centralizada, e a entidade PRODUTO também não faz parte do escopo de propagação. 


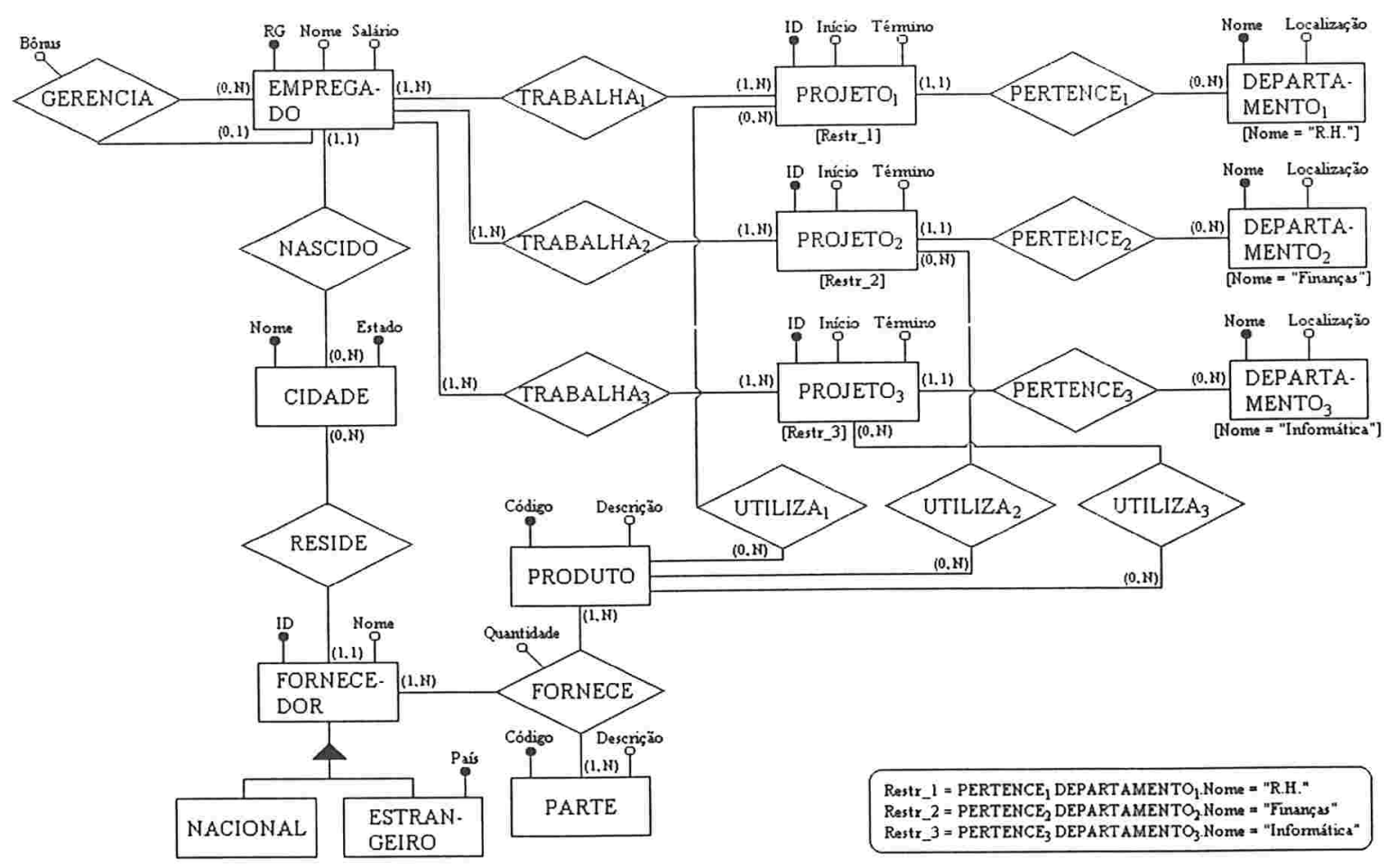

Figura 38: Fragmentação Horizontal Derivada

Porém, a empresa deseja que seus empregados sejam administrados diferentemente segundo seu nivel salarial pelo departamento de finanças, e estipulou o nivel divisório entre eles em $\mathrm{R} \$ 1.500,00$. Por este motivo, aplicamos uma fragmentação horizontal sobre a entidade EMPREGADO segundo seu nível salarial, e obtemos duas novas entidades, EMPREGADO, e EMPREGADO 2 , com seus respectivos conjuntos de restrições, [Salário $\leq$ $1.500]$ e [Salário > 1.500]. Tal fragmentação é ilustrada na Figura 39. 


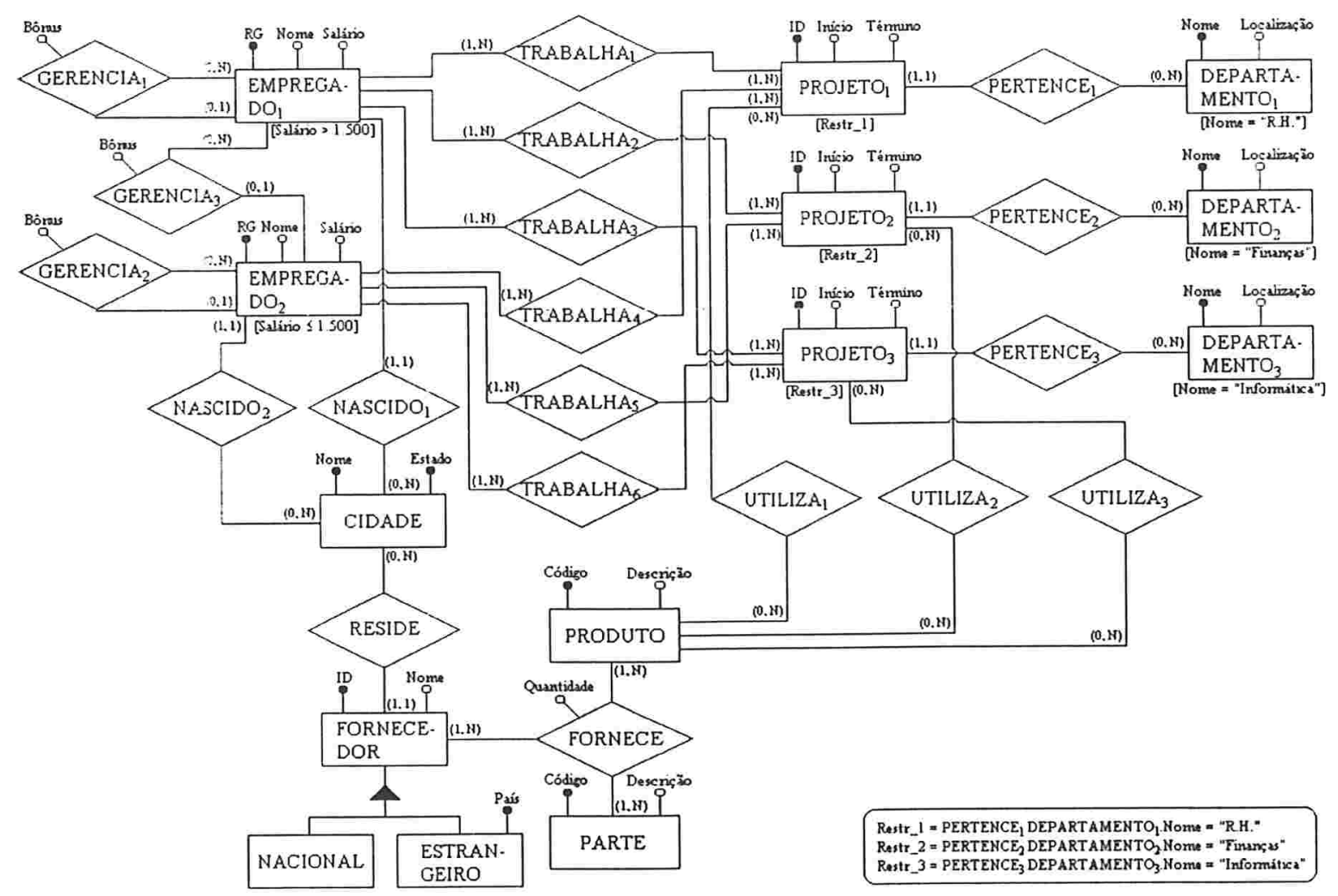

Figura 39: Diagrama ER Distribuido

A fragmentação realizada sobre a entidade EMPREGADO inicia um novo processo de análise da necessidade de propagação da fragmentação. Dessa vez, a única entidade a ser analisada é $C I D A D E$.

Observando o esquema, decidimos não propagar a fragmentação através da entidade $C I D A D E$, uma vez que tal operação não implicaria nenhum benefício para o esquema do banco de dados.

É importante notarmos que a fragmentação da entidade EMPREGADO produziu quatro relacionamentos GERENCLA, porém, conforme visto na seção 6-2, e admitindo que nenhum gerente possui salário inferior aos seus subordinados, o relacionamento que representa tal condição é vazio e não se apresenta no diagrama.

Assim, finalizamos o processo de distribuição, com esquema final representado na Figura 39. Vale lembrar que o modelo distribuído construído nesse exemplo acompanha toda a "vida" do banco de dados da empresa, devendo ser alterado para representar modificações que possam vir a ocorrer. 


\section{Greração da Imagem dos Fragmentos}

O conteúdo deste trabalho de pesquisa se encerra por aqui, mas o projeto do banco de dados não, ainda resta a fase do projeto físico. Na seção 3-1, ilustramos a relação entre os fragmentos e sua imagem física (Figura 13), a fim de oferecermos uma visão mais ampla do projeto de distribuição de um banco de dados.

Por isso, apresentaremos uma simples noção de como proceder com a geração da imagem física dos fragmentos, sem nos aprofundarmos no assunto. Para isso, utilizaremos o diagrama ER distribuído ilustrado na Figura 40, que apesar da sua simplicidade, exemplifica com satisfatoriedade a noção que nos propomos a passar.

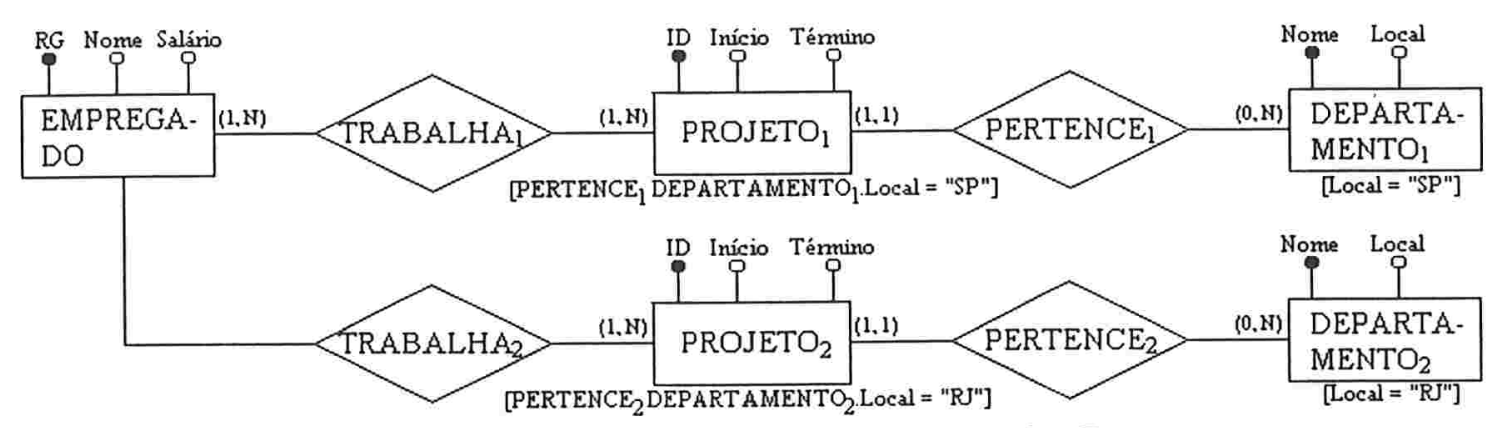

Figura 40: Diagrama ER para Geração da Imagem dos Fragmentos

Nosso método de fragmentação transforma um diagrama ER em um outro diagrama, mais complexo que o original. No entanto, este diagrama gerado ainda não é o produto final, pois devemos distribuí-lo. L'sando a terminologia da fragmentação relacional, precisamos gerar as imagens físicas, definimos imagens físicas no MER como um subconjunto conexo do diagrama ER resultante da fragmentação.

A uniào das imagens físicas deve reconstruir o diagrama final obtido. Em geral, uma imagem física contém no máximo um dos fragmentos de uma entidade fragmentada. Mas essa regra pode ser violada, por exemplo, no caso de haver replicaçào de entidades; replicações, no entanto, devem ser tratadas na fase de alocação dos fragmentos em máquinas hospedeiras, e, portanto, está fora do escopo deste trabalho.

A Figura 41 mostra uma possível geração de duas imagens físicas. Vale notar que há replicação da entidade EMPREGADO. Se desejarmos evitar esta replicação poderemos 
indicar que uma destas entidades é "virtual", talvez representando-a com linha tracejada. Obviamente, em alguma das imagens físicas a entidade não deve ser virtual.

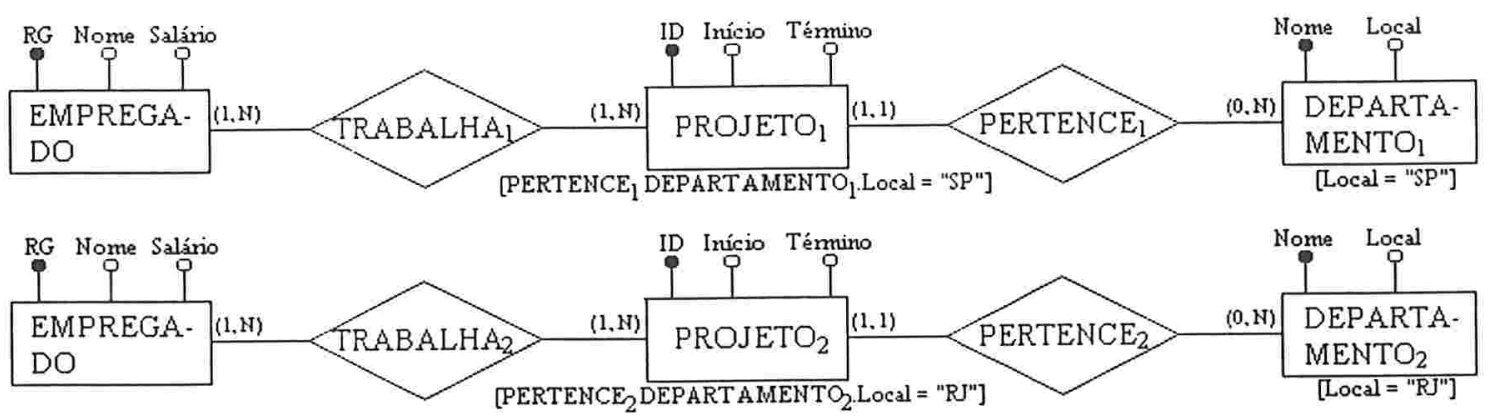

Figura 41: Imagem Física Conexa dos Fragmentos

A geração das imagens de fragmentos é um assunto complexo, se considerarmos diagramas ER maiores e com mais fragmentações, portanto não será abordado em maiores detalhes. 
Capítulo 7

\section{Conclusões}

A principal meta deste trabalho de pesquisa foi a de construirmos uma base sólida para a integração entre o projeto e a distribuição dos dados no nível conceitual. Desta maneira, o projeto de um banco de dados distribuído pode ser realizado sobre o seu esquema conceitual, e não, necessariamente, precisa da geração do esquema lógico para o início da fase de projeto físico.

A partir dos estudos realizados durante este projeto de pesquisa, algumas conclusões puderam ser obtidas, comprovando a viabilidade da filosofia apresentada através dos capítulos que compõem este texto. Tais conclusões referem-se à possibilidade de implementação de uma ferramenta computacional para o projeto e distribuição dos dados no nível conceitual; à proveniência estrutural das fragmentações horizontais derivadas; à incorporação do esquema conceitual na vida do banco de dados e à criação de uma base teórica para a manipulação de dados.

As próximas seções deste capítulo destinam-se ao comentário sobre as conclusões preliminares supracitadas respectivamente.

\section{Ferramenta para Projeto e Distribuição de Dados}

Os conceitos e a sistemática apresentados neste trabalho de pesquisa constituem uma base teórica bastante para a implementação de uma ferramenta computacional que possibilitasse a fragmentação "automática" de um DE-R. Tal implementação ilustraria a viabilidade e funcionalidade da aplicação da teoria desenvolvida durante este trabalho.

Segundo a idealização do autor, esta ferramenta seria composta por um editor de diagramas entidade-relacionamento, que englobaria todos os elementos do modelo ER apresentados no capítulo 2, além de um módulo de distribuiçào de dados. Este módulo de distribuição seria composto por um compilador simples para a realização de consultas baseadas na linguagem definida na seção 4-3, e um manipulador de visões, que controlaria a associação entre os diagramas inicial e fragmentado durante o processo de distribuição. 
A implementação da ferramenta encontra-se em estágio intermediário de desenvolvimento. O editor de diagramas entidade-relacionamento está completamente terminado, comportando todos os elementos previstos.

A finalização do sistema depende da implementação do módulo de distribuição, que está prevista para ser realizada em projetos futuros.

\section{A Natureza Estrutural das Fragmentações Derivadas}

No capítulo 3, onde apresentamos a teoria sobre distribuição de dados segundo o modelo relacional, pudemos notar a ausência de uma correspondência explícita e direta entre as relações globais que compõem o esquema lógico de um banco de dados. A correspondência entre relações é realizada em função de uma outra relação que possui atributos em comum entre estas relações, como por exemplo:

\section{FORNECEDOR(CGC, Nome, Telefone) FORNECE(CGC, NoSerial, Quantidade) PRODUTO No Serial, Descrição).}

As relações FORNECEDOR e PRODUTO estão relacionadas através da relação FORNECE, que possui os atributos chaves de ambas as relações, o que, sob nosso ponto de vista, não é um relacionamento explícito entre elas, mas arbitrário.

Uma fragmentação horizontal realizada sobre qualquer uma das relações FORNECEDOR ou PRODUTO, acarretaria na fragmentação direta da relação FORNECE, porém, o esquema lógico de dados apresentado no exemplo não torna explícita tal fragmentação derivada.

Consideremos o mesmo cenário utilizando o modelo ER ao invés do relacional. O diagrama que representa o esquema conceitual deste cenário pode ser visto na Figura 42.

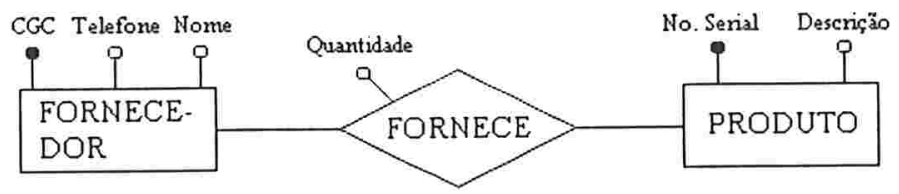

Figura 42: Diagrama ER (Conclusão) 
O relacionamento entre as entidades FORNECEDOR e PRODUTO torna-se explícito através do diagrama, uma característica semântica do modelo ER que o modelo relacional não possui.

Ao aplicarmos uma fragmentação horizontal sobre qualquer uma das classes de entidades FORNECEDOR ou PRODUTO a fragmentação horizontal derivada sobre a classes de relacionamentos FORNECE é direta e totalmente explícita através do diagrama, como podemos conferir no capítulo 5 , onde tratamos da fragmentação derivada primária.

Ao analisarmos os exemplo acima, podemos verificar que a estrutura representada no esquema conceitual no modelo ER, determina as fragmentações derivadas.

Em [6], o autor refere-se à fragmentação derivada de relações (no modelo relacional) como decorrente das consultas da aplicação de banco de dados, de onde podemos extrair que o esquema lógico que representa o banco de dados é construído em relação às consultas que serão efetuadas sobre ele.

No caso do modelo ER, pode-se facilmente notar que tanto as consultas, quanto as fragmentações derivadas, são decorrentes totalmente da estrutura do diagrama ER que representa conceitualmente o banco de dados. O que nos mostra uma inversão de conceitos no que tange ao projeto de um banco de dados nos diferentes modelos de dados.

\section{Incorporação do Esquema Conceitual na Vida do Banco de Dados}

Atualmente, a maioria dos projetistas de bancos de dados utiliza-se do modelo ER como ferramenta inicial de projeto. Uma vez definido o esquema conceitual do banco de dados, inicia-se a fase de projeto lógico, ou seja, ocorre a tradução do esquema conceitual para uma estrutura que possa ser manipulada por um SGDB (Sistema Gerenciador de Banco de Dados). O modelo lógico mais comumente utilizado nesta fase de projeto é o modelo relacional.

Após a tradução terminada, o esquema conceitual é abandonado, e todas as alterações que possivelmente venham a ocorrer são efetuadas sobre o esquema lógico, bem como a distribuição do banco de dados, e o esquema conceitual, na maioria dos casos, não é modificado. Para o caso de distribuição, o esquema conceitual não possui estruturas para representação de distribuição. 
Com a utilização da teoria apresentada neste trabalho é possível que o modelo conceitual possa ser utilizado como uma ferramenta permanente para o projeto de bancos de dados. Desta maneira, a documentação do projeto tornar-se-ia mais fácil e abstrata, em decorrência da representação semântica fornecida pelo modelo ER.

A representação de distribuição de dados no modelo ER possibilita que o esquema conceitual acompanhe a "vida" do banco de dados, tornando-o parte integrante e indispensável ao bom funcionamento do mesmo.

\section{Criação de uma Base Teórica para a Manipulação de Dados}

Conforme mencionado na seção 7-3, as idéias sugeridas neste projeto de pesquisa tornam o esquema conceitual um elemento componente da "vida" do banco de dados.

Uma das principais metas deste trabalho foi a criação de uma base teórica que possibilitasse a incorporação de manipulação de dados ao modelo ER para o caso de bancos de dados distribuídos. Uma vez que já temos a especificação de distribuição no modelo ER, a manipulação de dados pode ser realizada com base no projeto TEMPORA [7, 8, 9, 10, 11]. Este implementa a manipulação de dados no nível conceitual para bancos de dados centralizados, desenvolvido no Imperial College em Londres, do qual o Prof. Dr. Marcelo Finger (orientador) fez parte do grupo de desenvolvimento.

Com a manipulação de dados sendo realizada também no nível conceitual, praticamente todo o controle sobre o banco de dados seria realizado no nível conceitual. Por isso, podemos afirmar que este trabalho de pesquisa ampliou as possibilidades para tal progresso. 
Capítulo 8

\section{Bibliografia}

[1] P. Chen. The Entity-Relatioship model: Toward a unified view of data. ACM TODS, vol. 1, No. 1, 1976.

[2] C. Batini, S. Ceri, e S. Navathe. Conceptual Database Design - An Entity-Relationship Approach. The Benjamin/Cummings Publishing Company, Inc., 1992.

[3] R. Elmasri e S. Navathe. Fundamentals of Database Systems. The Benjamin/Cummings Publishing Company, 1989.

[4] H. Korth e A. Silberschatz. Sistema de Bancos de Dados. Editora McGraw-Hill, Ltda., 1989.

[5] S. Spaccapietra e C. Parent. An Algebra for a General Entity-Relationship Model. In IEEE Transactions on Software Engineering, vol. SE-11, No. 7, 1985.

[6] S. Ceri, G. Pelagatti. Distributed Databases - Principles and Systems. McGraw-Hill, Inc., 1984.

[7] P. Loucopoulos, P. J. McBrien, F. Schumacker, B. Theodoulidis, V. Kopanas, and B. Wangler. Integrating database teclbnology, rule-based sy'stems and temporal reasoning for effective software: the TEMPORA paradigm. Journal of Information Systems, 1(2), 1991.

[8] P. J. McBrien. The TEMPORA implementation: Oterview, testing and assessment. Technical report, TEMIPORA project report, November 1993. 


\section{Capítulo 8 - Bibliografia}

[9] P. J. McBrien, M. Niezette, S. Pantazis, B. Theodoulidis, G. Tziallas, A. H. Seltveit, U.Sundin, and R. Wohed. The TEMPORA external mule language. In Proceedings of the Third Nordic Conference on Advanced Information Systems Engineering, vol. 498 of LNCS. Springer-Verlag, 1991.

[10] TEMPORA project report. The sweden post case study. SISU, 1991.

[11] TEMPORA project report. The TEMPORA manual. BIM, 1992.

[12] V. Setzer. Projeto Lógico e Projeto Físico de Bancos de Dados. In V Escola de Computação,
Belo Horizonte - MG 1986 . [13] A. M. Neto. Uma Linguagem de Consulta para o Modelo ER e sua Completude. Dissertação
de Mestrado - IME - USP, 1982. 